\title{
Hepatitis B in At-Risk Groups: Three Studies to Guide Education, Testing, and Vaccination Efforts in West Virginia
}

\author{
Stacy Tressler \\ West Virginia University, sriffee@mix.wvu.edu
}

Follow this and additional works at: https://researchrepository.wvu.edu/etd

Part of the Epidemiology Commons

\section{Recommended Citation}

Tressler, Stacy, "Hepatitis B in At-Risk Groups: Three Studies to Guide Education, Testing, and Vaccination Efforts in West Virginia" (2020). Graduate Theses, Dissertations, and Problem Reports. 7625.

https://researchrepository.wvu.edu/etd/7625

This Dissertation is protected by copyright and/or related rights. It has been brought to you by the The Research Repository @ WVU with permission from the rights-holder(s). You are free to use this Dissertation in any way that is permitted by the copyright and related rights legislation that applies to your use. For other uses you must obtain permission from the rights-holder(s) directly, unless additional rights are indicated by a Creative Commons license in the record and/ or on the work itself. This Dissertation has been accepted for inclusion in WVU Graduate Theses, Dissertations, and Problem Reports collection by an authorized administrator of The Research Repository @ WVU.

For more information, please contact researchrepository@mail.wvu.edu. 
Hepatitis B in At-Risk Groups: Three Studies to Guide Education, Testing, and Vaccination Efforts in West Virginia

Stacy Tressler

Dissertation submitted to the School of Public Health at West Virginia University

In partial fulfillment of the requirements for the degree of Doctor in Philosophy in Epidemiology

\author{
Thomas Hulsey, ScD, Committee Chair \\ Gordon Smith, MD \\ Judith Feinberg, MD \\ Brian Hendricks, PhD
}

Department of Epidemiology

Morgantown, West Virginia

2020

Keywords: Hepatitis B; Hepatitis B Vaccine; At-risk Adults; Interventions; Geospatial Trends Copyright 2020 Stacy Tressler 


\begin{abstract}
Hepatitis B in At-Risk Groups in West Virginia: Three Studies to Guide Education, Testing, and Vaccination Efforts

Stacy Tressler
\end{abstract}

Background and Objectives: For over a decade, West Virginia's (WV) rate of acute hepatitis B has been the highest in the United States (US). In 2017, WV's rate was 11.7 per 100,000 population, almost 12 times higher than the national rate. The increase in acute hepatitis B cases is largely due to substance misuse, including injection drug use (IDU). Hepatitis B is a vaccine preventable disease yet many at-risk adults remain unvaccinated and susceptible to infection. The objectives of our studies are to 1) describe yearly changes in acute hepatitis B incidence in WV and assess county-level impact of the WV Pilot Project using geospatial methods 2) assess hepatitis B vaccine dose completion by setting type in at-risk groups and 3) understand factors associated with hepatitis B virus (HBV) exposure in an emerging at-risk group of people who report using methamphetamine.

Methods: Study 1. County rates of acute hepatitis B and vaccine doses per 100,000 population were visualized biannually from 2011 to 2018. Local indicators of spatial autocorrelation were used to detect county-level clustering. Significant differences in the median rate of acute hepatitis B pre and post intervention in counties receiving vaccine were evaluated using Wilcoxon signed-rank test and bootstrapping estimates. A Bland-Altman graph visualized significant differences in county-level rates of acute hepatitis B before and after the WV Pilot Project compared to the statewide estimate. Study 2. Deidentified data were collected from local health departments (LHDs) receiving hepatitis B vaccine through the WV Pilot Project and for which participant forms were available. The odds of receiving all three or at least two doses of hepatitis B vaccine were calculated using bivariate, multivariable, and mixed-effects regression models. Study 3. National Health and Nutrition Examination Survey data were utilized to examine factors associated with HBV exposure among participants who reported ever using methamphetamine using bivariate and multivariable logistic regression.

Results: Study 1. Analyses identified significant geographic clustering of acute hepatitis B in southern WV across all four time-periods. Nine of the 18 (50\%) counties receiving vaccine had significant declines in acute hepatitis B incidence compared to the statewide mean difference estimate. Study 2. Ten LHDs had data available representing 1,201 participants. In multivariable logistic regression, participants vaccinated at substance use treatment centers (aOR: 1.37; 95\% CI: 1.01-1.86) and LHD family planning clinics (aOR: 3.74; 95\% CI: 1.98-7.06) were more likely to receive the three-dose series compared to those vaccinated at LHD STD clinics. For the secondary outcome, participants vaccinated through substance use treatment centers (aOR: 1.79; 95\% CI: 1.31-2.44), correctional facilities (aOR: 3.34; 95\% CI: 2.09-5.34), and LHD family planning clinics (aOR: 3.97 ; 95\% CI: 1.72-9.16) were significantly more likely to receive at least two doses. Study 3. Overall, 847 participants representing approximately 11,048,115 people, met the study inclusion criteria. In multivariable logistic regression, female sex (aOR 3.83, 95\% CI $1.65-8.90)$, living below the poverty threshold (aOR 3.17, 95\% CI 1.39-7.21), injection drug use (IDU) (aOR 4.89, 95\% CI 1.95 - 12.26), active hepatitis C (HCV) infection (aOR 3.39, 95\% 
CI 1.10 - 12.26), and identifying as men who have sex with men (aOR 28.21, 95\% CI 5.19 153.38) were significantly associated with HBV exposure.

Conclusions: Despite the availability of a safe and effective hepatitis B vaccine, many individuals remain at risk of infection. Hepatitis B virus transmission continues in WV due in part to injection drug use and substance misuse. Ongoing efforts are needed to identify trends, guide testing and vaccination programs, and evaluate the effectiveness of those programs.

Increased dissemination of hepatitis B vaccine through local health departments and existing harm reduction services can reduce the incidence of acute hepatitis B in states such as WV, which have been disproportionately affected by substance misuse. 


\section{TABLE OF CONTENTS}

Page

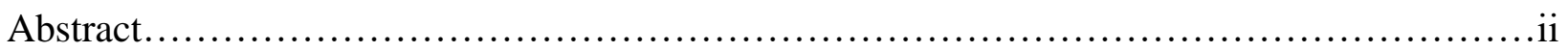

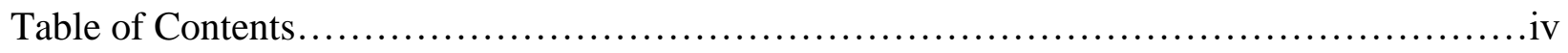

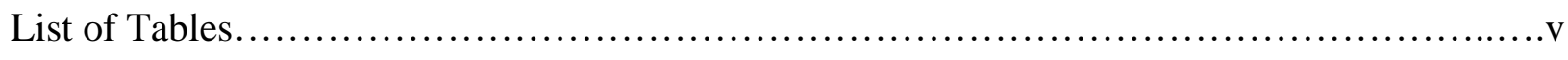

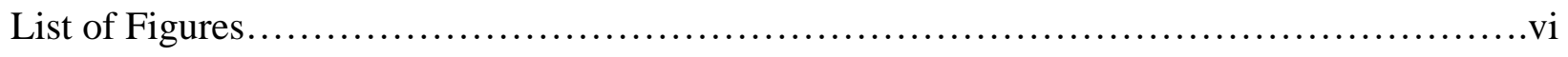

List of Nomenclature and Abbreviations.............................................. vii

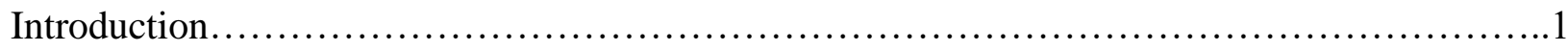

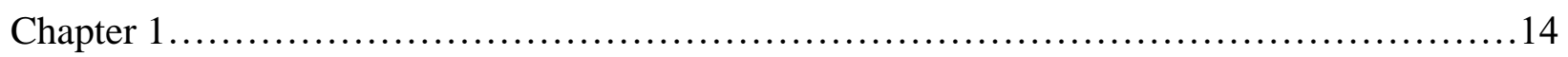

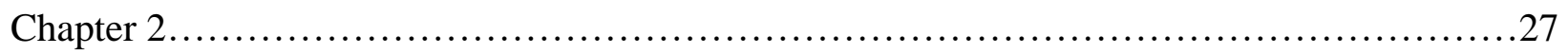

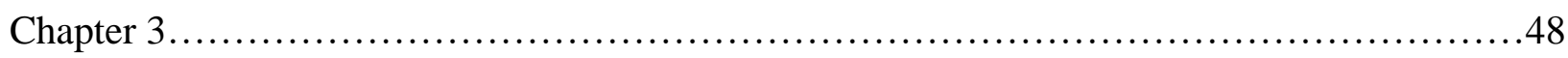

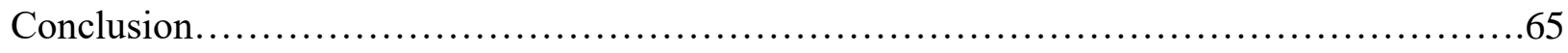

Appendices.................................................................69

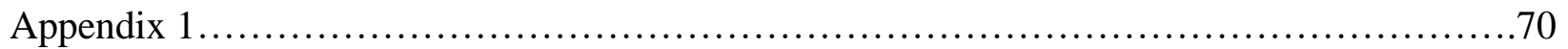




\section{LIST OF TABLES}

Table 2.1

Table 2.2

Table 2.3
Supplementary

Table 2.1

Supplementary

Table 2.2

Supplementary

Table 2.3

Table 3.1

Table 3.2
Setting type and demographics of WV Pilot Project participants and primary and secondary outcomes

Unadjusted odds ratios for exposure variables and primary and secondary objectives

Adjusted odds ratios for exposure variables and primary and secondary objectives

\section{N}

Number of WV Pilot Project participants vaccinated through each local health department by setting type

Page 46

Page 46

Project setting type

Frequency and percentage of doses received by WV Pilot
Page 42

Page 44

Page 45

\section{Project setting type}
Mixed-effects model adjusted odds ratios controlling for local health department as a random effect

Page 47

Page 60

Descriptive statitics, weighted percents, weighted frequencies, and standard errors for exposure variables and HBV status

Unadjusted and adjusted odds ratios for association between exposure variables and HBV status 


\section{LIST OF FIGURES}

Figure 1

Figure 2

Figure 3

Figure 1.1

Figure 1.2

Figure 1.3

Figure 2.1

Figure 3.1
Acute Hepatitis B Incidence Rate per 100,000 Population West Virginia \& United States, 1996 - 2017

Hepatitis B \& Hepatitis C Incidence Rate per 100,000 Population \& Age-adjusted Drug Overdose Mortality Rate per 100,000

Population - West Virginia, 2007-2017

Number of Fatal Drug Overdose Deaths and Select

Substances - West Virginia, 2001-2018

West Virginia county-level rates of acute hepatitis B from 2011 through 2018 and vaccine doses per 100,000 population

West Virginia acute hepatitis B cluster analyses and vaccine doses per 100,000 population

Page 9

Page 24

Page 25

Page 26 Bland-Altman graph depicting the difference in acute hepatitis B Project counties compared to the mean difference for all of West Virginia before and after WV Pilot Project implementation

Flow chart of sample selection process

Page 41

Page 59 


\section{LIST OF NOMENCLATURE AND ABBREVIATIONS}

\begin{tabular}{|c|c|}
\hline ACIP & Advisory Committee on Immunization Practices \\
\hline anti-HBc & Hepatitis B core antibody \\
\hline $\mathrm{CDC}$ & Centers for Disease Control and Prevention \\
\hline CI & Confidence Interval \\
\hline DIDE & Division of Infectious Disease Epidemiology \\
\hline DNA & Deoxyribonucleic acid \\
\hline $\mathrm{HBsAb}$ & Hepatitis B surface antibody \\
\hline HBsAg & Hepatitis B surface Antigen \\
\hline $\mathrm{HBV}$ & Hepatitis B virus \\
\hline $\mathrm{HCC}$ & Hepatocellular carcinoma \\
\hline $\mathrm{HCV}$ & Hepatitis C Virus \\
\hline HIV & Human immunodeficiency virus \\
\hline HSV & Herpes simplex virus \\
\hline IDU & Injection drug use \\
\hline IRB & Institutional review board \\
\hline LISA & Local indicators of spatial autocorrelation \\
\hline MSM & Men who have sex with men \\
\hline NCHS & National Center for Health Statistics \\
\hline OEPS & Office of Epidemiology \& Prevention Services \\
\hline OR & Odds ratio \\
\hline LHD & Local health department \\
\hline
\end{tabular}


NHANES

PWID

RNA

RR

STD

US

WHO

WV
National Health \& Nutrition Examination

People who inject drugs

Ribonucleic acid

Risk ratios

Sexually transmitted disease

United States

World Health Organization

West Virginia 


\section{INTRODUCTION}

Hepatitis B is a liver disease resulting from infection with hepatitis B virus (HBV); a small partially double stranded DNA virus that infects humans [1]. The virus is spread through contact with blood and body fluids, is highly infectious, and environmentally stable; remaining viable on surfaces at room temperature for up to seven days [2]. HBV is estimated to be ten time more infectious than the hepatitis $\mathrm{C}$ virus $(\mathrm{HCV})$ and one hundred times more infectious than human immunodeficiency virus (HIV) [3].

Infection with HBV results in an acute infection that may or may not be accompanied by signs and symptoms. Symptoms include fatigue, loss of appetite, nausea, vomiting, right upper quadrant pain, fever, headache, myalgia, dark urine, and jaundice $[4,5]$. More than $85 \%$ of children and 50\% of adults are asymptomatic [4]. The incubation period ranges from 45 days to 160 days with an average of 90 days [6]. People acutely infected are able to transmit the virus one to two months before and after the onset of symptoms. About $1 \%$ of people acutely infected with HBV will develop fulminant hepatitis possibly resulting in death [7]. Acute infection can progress to a life-long chronic infection with age being the greatest factor in progression to chronicity [5, 8, 9]. Approximately, 90 to $95 \%$ of infants infected at birth will develop a chronic infection while only 5 to $10 \%$ of adults will progress to the chronic carrier state $[9,10]$. About $50 \%$ of people chronically infected are unaware of their infection and remain a source of ongoing transmission $[11,12]$.

Hepatitis B virus infects liver cells resulting in chronic inflammation. Complications of chronic infection with HBV include cirrhosis, liver failure, hepatocellular carcinoma (HCC), and death $[6,10]$. It is estimated that chronic infection is responsible for 50\% of all cases of HCC and $25 \%$ of people with chronic infection will die prematurely from complications of the disease [11, 13]. There is no cure for hepatitis B, only treatment to slow the progression of disease.

Hepatitis B is a significant public health problem worldwide. Almost $90 \%$ of the world's population live in countries with either a high prevalence (greater than $8 \%$ ) or intermediate prevalence (between $2 \%$ and $7 \%$ ) of hepatitis B $[14,15]$. Those living in high prevalence areas have a greater than $60 \%$ lifetime risk of acquiring hepatitis B while those living in an intermediate areas have a lifetime risk between $20 \%$ and $60 \%$ [14]. In countries with high or intermediate hepatitis B prevalence, most infections occur via vertical transmission during 
childbirth or are acquired during childhood [16-18]. Estimates of the number of people chronically infected with HBV are as high as 350 million. The World Health Organization (WHO) estimates that globally approximately $3.5 \%$ of the world's population (257 million people) are living with chronic HBV infections and an estimated 887,000 people died in 2015 as a result from disease complications $[17,19]$. If current rates of hepatitis B remain unchanged, 20 million people are projected to die from HBV related disease complications by 2030 [16]. Due to the global burden of all types of viral hepatitis, the WHO has developed a strategy to eliminate viral hepatitis as a public health threat by 2030 [16].

In the US, the incidence of acute hepatitis B infections has decreased $75 \%$ over the past three decades largely due to the implementation of universal vaccination of infants at birth in 1991 and recommendation of catch-up vaccination of adolescents in 1997 [20-22]. Despite decreases in the incidence of new infections, an estimated 800,000 to 2.2 million people are living with chronic infections [5, 23]. Estimates using National Health and Nutrition Survey (NHANES) data indicate the prevalence of chronic hepatitis B in the United States has remained around 0.3\% since 1999 due in part to immigration of foreign-born persons from endemic countries [24]. Approximately, $70 \%$ of people chronically infected persons in the United States are foreign-born with nearly 50\% of chronic infections occurring in non-Hispanic Asians [5, 23].

Since 2006, the rate of acute HBV infections in the U.S. has remained stable at around 1 case per 100,000 people $[25,26]$. Major risk factors for acute HBV infection in the U.S. include injection drug use and multiple sexual partners [26]. Over the past decade, substance misuse has resulted in a resurgence in cases of acute hepatitis B in certain high-risk groups including people who inject drugs (PWID) [27, 28]. Nationwide, in 2015 the highest incidence of acute hepatitis B occurred among persons 30 to 39 years of age with $30 \%$ of newly infected people reporting IDU as a risk factor [28]. Most notably, there was a substantial increase in acute hepatitis B cases in parts of central Appalachia including Kentucky, Tennessee, and West Virginia (WV). From 2009-2013, there was a 114\% increase in the number of newly reported acute infections in these three states [25]. The majority of cases occurred among non-Hispanic whites, 30 to 39 years of age with $75 \%$ reporting IDU as a risk factor [25].

PWID are at an increased risk of becoming infected with HBV through sharing of equipment to inject drugs and sexual contact [29]. Estimates of the non-institutionalized U.S. population 
indicate that around $19.7 \%$ to $27.3 \%$ of PWID have serological lab markers consistent with past or present infection compared to just $4.6 \%$ of the general population [30, 31]. Adults with compromised immune systems are more likely to develop chronic infections and PWID may have a higher risk of developing chronic infection due to altered immune function and coinfections with HCV and HIV [11, 32, 33]. Co-infections coupled with chronic drug use can result in increased morbidity and mortality as well as accelerated progression of liver disease [29]. Hepatitis B vaccination is recommended for PWID but despite this recommendation vaccination rates among PWID remains low [34]. Only an estimated $15 \%$ to $20 \%$ of PWID have lab markers consistent with vaccine-induced immunity compared to $23 \%$ to $30 \%$ of U.S. adults [31, 35, 36]. From 2003 to 2014, seroprevalence of vaccine-induced immunity increased in the general U.S. population but not in PWID, men who have sex with men (MSM), and people with chronic hepatitis C [35]. Low vaccination rates coupled with high-risk behaviors and reduced immune response to the vaccine means that many at-risk individuals remain vulnerable to acquiring $\mathrm{HBV}[32,33]$.

Rural areas have been disproportionately affected by the opioid crisis and disease transmission associated with IDU. An outbreak of HIV associated with IDU in rural Scott County prompted a nationwide county-level vulnerability of assessment to identify counties at high-risk for a similar outbreak [37, 38]. The assessment identified 220 counties in 26 states at risk for HIV and HCV transmission among PWID [38]. Twenty-eight of the 220 counties identified by the assessment were in WV, with two WV counties ranking in the top 10 (McDowell \#2 and Mingo \#7) [38]. Existing high rates of acute hepatitis B in WV coupled with vulnerability to outbreaks of infections associated with IDU, indicates the potential for ongoing transmission of HBV along with the risk of co-infections with HIV and HCV.

Despite decreasing trends nationwide, the rate of new HBV infections in WV has steadily increased since 2002 (Figure 1) [39]. In 2016, WV's rate of acute hepatitis B was 14.7 per 100,000, almost 15 times the national average [40]. Since 2006, WV has ranked first in the nation with the highest rate of acute hepatitis $\mathrm{B}$ and either first or second for acute hepatitis $\mathrm{C}$ [26]. West Virginia rates of acute hepatitis B and hepatitis $C$ have mirrored overdose mortality rates (Figure 2). From 2012-2016, the rate of acute hepatitis B cases was highest among males, persons 30 to 39, and cases were concentrated in the southern region of the state [41]. In 2016, 
the most common risk factors reported in WV among people with acute hepatitis B was IDU or street drug use [42]. Given ongoing issues of substance misuse across WV, transmission of hepatitis B will continue among at-risk groups unless additional efforts are made to identify and prevent HBV infections in those with the highest risk of exposure.

Along with opioid use, nationwide use of methamphetamine is rising due to an increase in the availability of cheaper, more potent methamphetamine flooding the US from Mexico [43, 44]. From 2010 to 2018, the number of methamphetamine seizures at the US border increased dramatically from 8,900 pounds to 82,000 respectively [44]. Methamphetamine use in the US peaked around 2005 but has reemerged as a threat in recent years [43, 45]. From 2011 to 2016, the number of overdose deaths involving methamphetamine more than tripled and accounted for $11 \%$ of overdose deaths in 2016. Additionally, a recent study found methamphetamine use almost doubled from $18.8 \%$ in 2011 to $34.2 \%$ in 2017 among people using opioids who sought treatment in the US [46].

Hepatitis B in people who use methamphetamine is not well described in the literature but its use, either through parenteral or non-parenteral routes, increases the risk for acquiring sexually transmitted infections including hepatitis B [47]. Recently, methamphetamine has been implicated in an increase in acute hepatitis B cases, as well as an increase in hepatitis C, HIV, and syphilis in the US and parts of Canada [48, 49]. In line with nationwide trends, overdose trends in WV suggest methamphetamine use is increasing across the state. In WV, the number of overdose deaths involving methamphetamine increased from 49 in 2015 to 323 in 2018 with $36 \%$ of all overdose deaths in 2018 involving methamphetamine (Figure 3) [50, 51]. The increase in methamphetamine use and co-use with opioids represents a public health threat requiring a refocusing of response efforts in WV.

Hepatitis B remains a real and ongoing threat to a number of at-risk groups, including people who use drugs and those engaging in high-risk sexual behaviors. It is recommended that at-risk people without serological evidence of HBV infection or immunity be vaccinated against HBV [27]. As substance misuse continues in WV, it is important to understand factors associated with HBV exposure among at-risk populations to help guide education, testing, and vaccination efforts.

\section{Purpose Statement:}


The objectives of our studies are to describe yearly changes in acute hepatitis B incidence and assess county-level impact of the WV Pilot Project using geospatial methods, assess hepatitis B vaccine dose completion by setting type in at-risk groups, and understand factors associated with HBV exposure in an emerging at-risk group of people using methamphetamine. Study findings will contribute to knowledge about changes in the geographic distribution of hepatitis B in WV to help inform surveillance activities and placement of harm reduction services. Additionally, results will improve future vaccination programs and efforts among individuals at risk of HBV infection.

Specific Aim 1. Use geospatial methods to examine changes in the distribution of acute hepatitis B in West Virginia in relation to counties participating in the WV Pilot Project.

Purpose of Study 1. Despite having the highest rate of acute hepatitis B for over a decade, spatial trends in WV have not been examined over time. Visualizing trends and conducting cluster analyses can inform placement of harm reduction services, identify areas in need of enhanced surveillance, guide future vaccination efforts, and help evaluate the impact of interventions. Our study will incorporate a variety of geospatial methods to assess county-level distribution of acute hepatitis B rates before, during, and after the WV Pilot Project, identify county-level hotspots, and identify areas in need of additional hepatitis B prevention efforts.

Specific Aim 2. Determine which setting type is associated with higher odds of completing all three or at least two doses of hepatitis B vaccine among at-risk individuals vaccinated through local health departments as part of a vaccine pilot project.

Purpose of Study 2. Completion of the three-dose hepatitis B vaccination among at-risk adults remains a challenge. Despite WV's participation in two federally funded hepatitis B vaccine initiatives (Adult Hepatitis B Vaccination Initiative, 2007-2009 and HepB Pilot Program, 20132015), the effectiveness of such initiatives has not been evaluated. Our study will examine factors associated with completion of the three-dose hepatitis B vaccine in local health departments. Findings from this study will be valuable in informing future vaccination efforts among at-risk populations. There is a gap in the literature regarding strategies to increase hepatitis B vaccination in at-risk groups in rural areas. Given current drug misuse in Appalachia, this is an especially important and timely topic for both hepatitis A and B. 
Specific Aim 3. Identify factors associated with HBV exposure among people who report using methamphetamine.

Purpose of Study 3. People who use methamphetamine are at an increased risk of exposure from high-risk sexual behaviors and equipment used to administer the drug. Documented increases in reported methamphetamine use among people diagnosed with primary and secondary syphilis indicates there is an association between methamphetamine use and risky sexual behaviors [49]. Our study will examine factors associated with methamphetamine use and HBV exposure to identify groups potentially at an increased risk of infection. 
Figure 1. Acute Hepatitis B Incidence Rate per 100,000 Population in West Virginia \& United States, 1996 - 2017

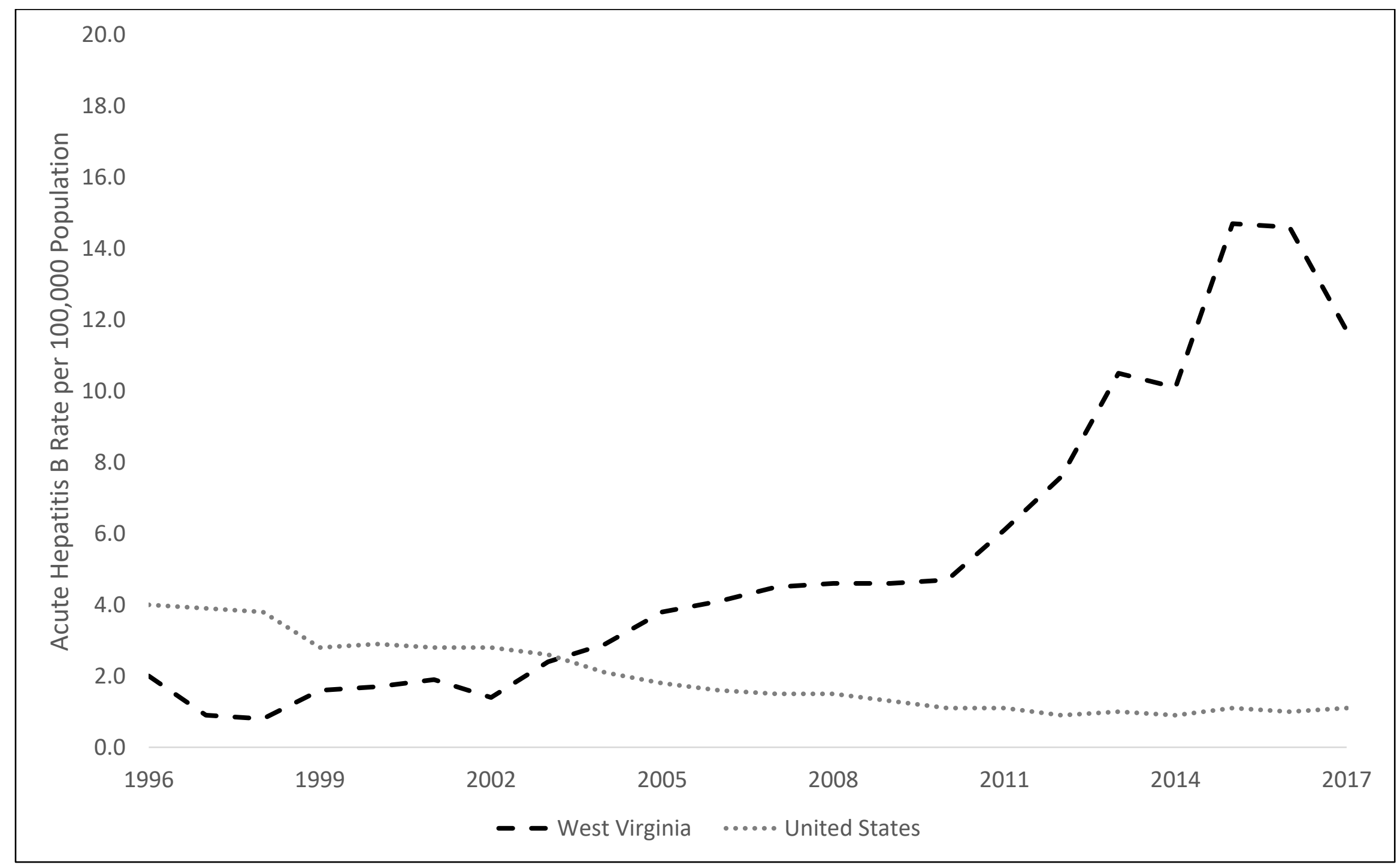

Data source: Centers for Disease Control and Prevention, Viral Hepatitis Statistics and Surveillance [26] 
Figure 2. Hepatitis B \& Hepatitis C Incidence Rate per 100,000 Population \& Age-adjusted Drug Overdose Mortality Rate per 100,000 Population — West Virginia, 2007-2017

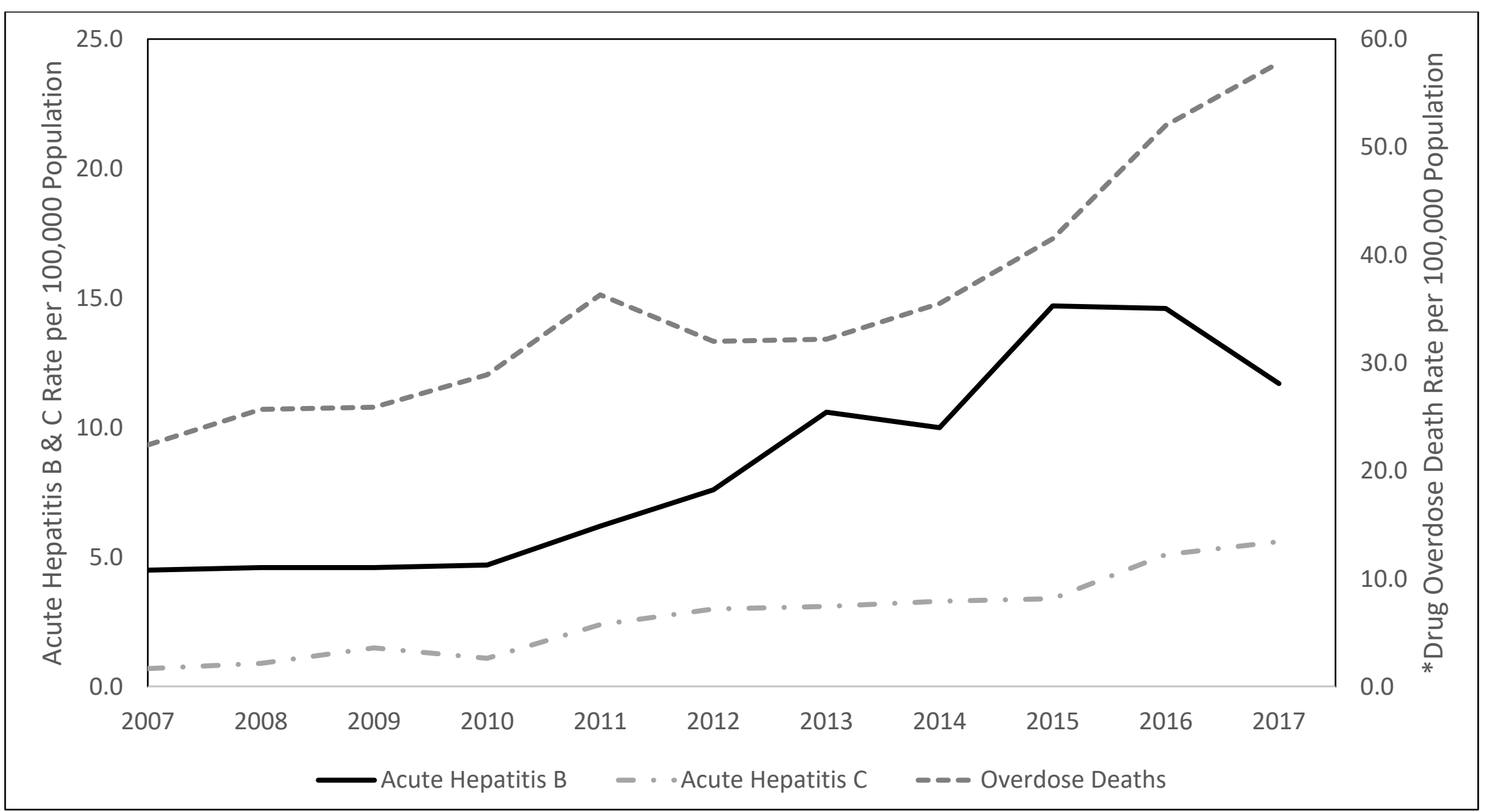

*Age-Adjusted; Data sources: WV Office of Epidemiology and Prevention Services [52], Centers for Disease Control and Prevention, Drug Overdose Death Rates [53], Centers for Disease Control and Prevention, Viral Hepatitis Statistics and Surveillance [26] 
Figure 3. Number of Fatal Drug Overdose Deaths and Select Substances — West Virginia, 2001-2018

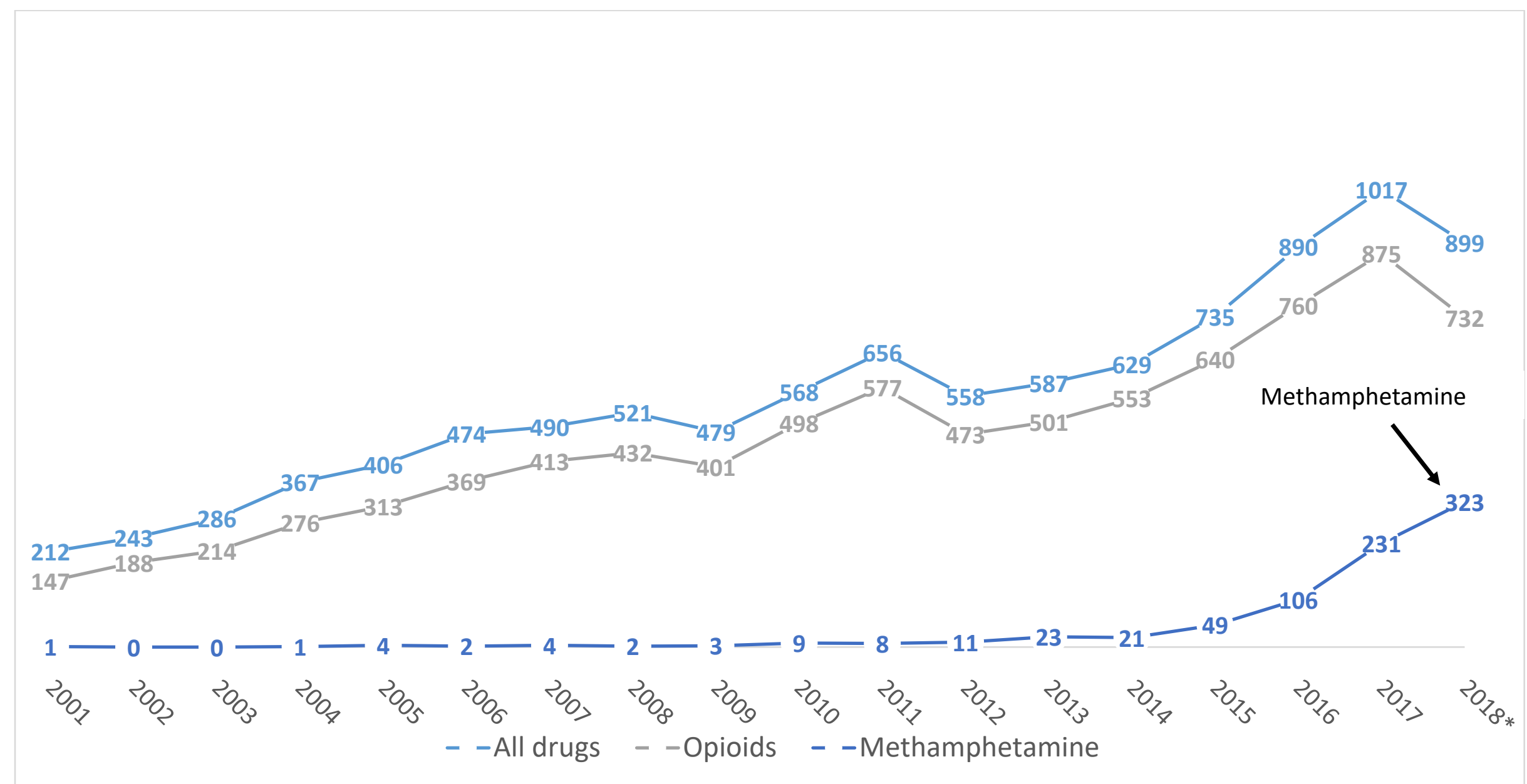

*2018 data are provisional; Data source: West Virginia Health Statistics Center, Vital Statistics System, Drug Overdose Database [50, 51] 


\section{LITERATURE CITED}

1. Ganem D, Prince AM. Hepatitis B virus infection—natural history and clinical consequences. N Engl J Med. 2004;350(11):1118-1129.

2. Than TT, Jo E, Todt D, et al. High environmental stability of hepatitis B virus and inactivation requirements for chemical biocides. J Infect Dis. 2019;219(7):1044-8.

3. Khan F, Shams S, Qureshi ID, et al. Hepatitis B virus infection among different sex and age groups in Pakistani Punjab. Virol J. 2011;8:225.

4. Centers for Disease Control and Prevention. The ABCs of hepatitis fact sheet. https://www.cdc.gov/hepatitis/resources/professionals/pdfs/ABCTable.pdf. Updated 2016. Accessed 16 June 2019.

5. Weinbaum C, Williams I, Mast E, et al. Recommendations for identification and public health management of persons with chronic hepatitis B virus infection. MMWR Recomm Rep. 2008;57(RR-8):1-20.

6. Kimberlin DW, Brady MT, Jackson MA, Long SS. Red Book. 30th ed. Elk Grove, IL. 2015 Report of the Committee on Infectious Diseases: American Academy of Pediatrics; 2015.

7. Lee WM. Acute liver failure. N Engl J Med. 1993; 329:1862-72.

8. McMahon BJ, Alward WL, Hall DB, et al. Acute hepatitis B virus infection: relation of age to the clinical expression of disease and subsequent development of the carrier state. J Infect Dis. 1985;151(4):599-603.

9. Edmunds WJ, Medley GF, Nokes DJ, Hall AJ, Whittle HC. The influence of age on the development of the hepatitis B carrier state. Proc Biol Sci. 1993;253(1337):197-201.

10. Lee WM. Hepatitis B virus infection. N Engl J Med. 1997; 337:1733-45.

11. Hepatitis B. In: Hamborsky J, Kroger A, Wolfe S, eds. Centers for Disease Control and Prevention. Epidemiology and prevention of vaccine-preventable diseases. 13th ed. Washington DC: Public Health Foundation, 2015; 149-174.

12. U.S. Department of Health \& Human Services. Hepatitis B basic information. Available at: www.hhs.gov/hepatitis/learn-about-viral-hepatitis/hepatitis-b-basics/index.html. Accessed 21 February 2020.

13. Xie Y. Hepatitis B virus-associated hepatocellular carcinoma. Infectious Agents Associated Cancers: Epidemiology and Molecular Biology: Springer, 2017:11-21.

14. Centers for Disease Control and Prevention. Screening for viral hepatitis during the domestic medical examination of newly arrived refugees. Available at:

www.cdc.gov/immigrantrefugeehealth/guidelines/domestic/hepatitis-screening-guidelines.html. Accessed 21 February 2020.

15. Trépo C, Chan HL, Lok A. Hepatitis B virus infection. Lancet. 2014; 384:2053-63. 
16. World Health Organization. Global health sector strategy on viral hepatitis 2016-2021. Towards ending viral hepatitis. World Health Organization. 2016.

17. World Health Organization. Global hepatitis report 2017. World Health Organization. 2017.

18. World Health Organization. Hepatitis B. Available at: www-whoint.www.libproxy.wvu.edu/en/news-room/fact-sheets/detail/hepatitis-b. Accessed February 23, 2020.

19. World Health Organization. Hepatitis B vaccines: WHO position paper - July 2017. Weekly epidemiological record: World Health Organization. 2017;27(92)369-392.

20. Van Buren RC, Schaffner W. Hepatitis B virus: a comprehensive strategy for eliminating transmission in the United States through universal childhood vaccination. Recommendations of the Immunization Practices Advisory Committee (ACIP). MMWR Recomm Rep 1991; 40:1-19.

21. Centers for Disease Control and Prevention. Update: recommendations to prevent hepatitis B virus transmission--United States. MMWR Recomm Rep 1999; 48:33.

22. Centers for Disease Control and Prevention. Viral Hepatitis Statistics \& Surveillance. Available at: https://www.cdc.gov/hepatitis/statistics/index.htm. Accessed 15 January 2020.

23. Kowdley KV, Wang CC, Welch S, Roberts H, Brosgart CL. Prevalence of chronic hepatitis B among foreign-born persons living in the United States by country of origin. Hepatology. 2012;56(2):422-433.

24. Roberts H, Kruszon-Moran D, Ly KN, et al. Prevalence of chronic hepatitis B virus (HBV) infection in U.S. households: National Health and Nutrition Examination Survey (NHANES), 1988-2012. Hepatology. 2016;63(2):388-97..

25. Harris AM, Iqbal K, Schillie S, Britton J, Kainer MA, Tressler S, et al. Increases in acute hepatitis B virus infections - Kentucky, Tennessee, and West Virginia, 2006-2013. MMWR Morb Mortal Wkly Rep. 2016;65(3):47-50.

26. Centers for Disease Control and Prevention. Viral hepatitis surveillance - United States. Available at: https://www.cdc.gov/hepatitis/statistics/SurveillanceRpts.htm. Accessed 3 March 2020 .

27. Schillie S, Vellozzi C, Reingold A, et al. Prevention of hepatitis B virus infection in the United States: Recommendations of the Advisory Committee on Immunization Practices. MMWR Recomm Rep 2018; 67:1-31.

28. Centers for Disease Control and Prevention. Hepatitis B questions and answers for health professionals. Available at: www.cdc.gov/hepatitis/hbv/hbvfaq.htm\#overview. Accessed 1 February 2020.

29. Walsh N, Verster A, Rodolph M, Akl EA. WHO guidance on the prevention of viral hepatitis B and C among people who inject drugs. Int J Drug Policy. 2014; 25:363-71. 
30. Shing JZ, Ly KN, Xing J, Teshale EH, Jiles RB. Prevalence of hepatitis B virus infection among US adults aged 20-59 years with a history of injection drug use: National Health and Nutrition Examination Survey, 2001-2016. Clin Infect Dis.

ciz669, https://doi.org/10.1093/cid/ciz669

31. Ioannou GN, 2011. Hepatitis B virus in the United States: infection, exposure, and immunity rates in a nationally representative survey. Ann Intern Med. 2011;154(5):319-328.

32. Tran TQ, Grimes CZ, Lai D, Troisi CL, Hwang L. Effect of age and frequency of injections on immune response to hepatitis B vaccination in drug users. Vaccine. 2012;30(2):342-9.

33. Hwang LY, Grimes CZ, Tran TQ, et al. Accelerated hepatitis B vaccination schedule among drug users: A randomized controlled trial. J Infect Dis. 2010; 202:1500-9.

34. Centers for Disease Control and Prevention. Integrated prevention services for HIV infection, viral hepatitis, sexually transmitted diseases, and tuberculosis for persons who use drugs illicitly: summary guidance from CDC and the U.S. Department of Health and Human Services. MMWR Recomm Rep. 2012; 61:1-40.

35. Yeo YH, Le MH, Chang ET, Henry L, Nguyen MH. Prevalence of undetectable vaccineinduced immunity against hepatitis B virus in US adults at high risk for infection. Hepatology. 2019;69(4):1385-97.

36. King H, Xing J, Dean HD, Holtzman D. Trends in prevalence of protective levels of hepatitis B surface antibody among adults aged 18-49 years with risk factors for hepatitis B virus infection-United States, 2003-2014. Clin Infect Dis. 2019 Jun 20.

37. Conrad C, Bradley HM, Broz D, et al. Community outbreak of HIV infection linked to injection drug use of oxymorphone--Indiana, 2015. MMWR Morb Mortal Wkly Rep. 2015; 64:443-4.

38. Van MH, Rose CE, Hallisey EJ, et al. County-level vulnerability assessment for rapid dissemination of HIV or $\mathrm{HCV}$ infections among persons who inject drugs, United States. $J$ Acquir Immune Defic Syndr. 2016; 73(3):323-31.

39. Daniels D, Grytdal S, Wasley A. Surveillance for acute viral hepatitis - United States, 2007. MMWR Surveill Summ. 2009: 58(3):1-27.

40. Centers for Disease Control and Prevention. Surveillance for viral hepatitis - United States, 2016. Available at: www.cdc.gov/hepatitis/statistics/2016surveillance/index.htm. Accessed 2 February 2020.

41. Anil L, Simmons A. West Virginia viral hepatitis B and C surveillance 2012-2015. West Virginia Department of Health and Human Resources Bureau for Public Health. 2016. Available at: http://dhhr.wv.gov/oeps/disease/viral-hepatitis/documents/Hepatitis-Report-2016.pdf. Accessed 2 February 2020. 
42. Office of Epidemiology and Prevention Services. Hepatitis B and hepatitis C infection in West Virginia - 2016 Surveillance Summary. Available at:

https://oeps.wV.gov/hepatitis/documents/data/Summary_2016_Acute_HBV-HCV.pdf. Accessed 3 March 2020.

43. The Lancet. Opioids and methamphetamine: a tale of two crises. Lancet 2018;391(10122):713.

44. U.S. Department of Justice Drug Enforcement Agency. 2018 national drug threat assessment. October 2018. Available at: https://www.dea.gov/sites/default/files/2018-11/DIR-03218\%202018\%20NDTA\%20final\%2010w\%20resolution.pdf. Accessed 3 March 2020.

45. Hedegaard H, Bastian BA, Trinidad JP, Spencer M, Warner M. Drugs most frequently involved in drug overdose deaths: United States, 2011-2016. Natl Vital Stat Rep. 2018: 67(9): 114.

46. Ellis MS, Kasper ZA, Cicero TJ. Twin epidemics: The surging rise of methamphetamine use in chronic opioid users. Drug Alcohol Depend. 2018: 193:14-20.

47. National Institute on Drug Abuse. Methamphetamine. Available at:

https://www.drugabuse.gov/publications/research-reports/methamphetamine/. Accessed 13 April 2019.

48. Pursaga J. Meth use causing hepatitis B outbreak in Winnipeg. Winnipeg Sun, 2018.

Available at: https://winnipegsun.com/news/news-news/meth-use-causing-hepatitis-b-outbreakin-winnipeg. Accessed 14 April 2019.

49. Kidd SE, Grey JA, Torrone EA, Weinstock HS. Increased methamphetamine, injection drug, and heroin use among women and heterosexual men with primary and secondary syphilis United States, 2013-2017. MMWR Morb Mortal WKLY Rep 2019; 68:144-8.

50. West Virginia Health Statistics Center - Vital Statistics System. Drug overdose deaths occurring in West Virginia. Drug Overdose Database. July 152019.

51. WV Health Statistics Center for the Statewide Epidemiological Outcomes Workgroup. West Virginia fatal rrug overdoses. Available at: https://dhhr.wv.gov/bhhf/Sections/programs/ProgramsPartnerships/AlcoholismandDrugAbuse/R esearch/Documents/SEOW\%20Meeting\%20Presentations/SEOW\%20WV\%20Fatal\%20Drug\%2 0Overdoses\%20Elizabeth\%20Larimore\%201.13.20.pdf. Accessed March 32020.

52. West Virginia Office of Epidemiology and Prevention Services. West Virginia drug overdose deaths historical overview 2001-2015. Available at:

https://dhhr.wV.gov/oeps/disease/ob/documents/opioid/wv-drug-overdoses-2001_2015.pdf.

Accessed 3 March 2020.

53. Centers for Disease Control and Prevention. Drug overdose deaths. Available at:

www.cdc.gov/drugoverdose/data/statedeaths.html. Accessed 3 March 2020. 


\title{
CHAPTER ONE
}

Impact of a Vaccine Intervention on County-Level Rates of Acute Hepatitis B in West Virginia, 2011-2018

\begin{abstract}
The rate of acute hepatitis B in West Virginia (WV) has been increasing since 2006. To reduce new infections, WV implemented a vaccine intervention (WV Pilot Project), which provided over 10,000 doses of hepatitis B vaccine to at-risk adults in 18 counties. The objectives of this study were to describe yearly changes in acute hepatitis B incidence and assess county-level impact of the WV Pilot Project using geospatial methods. County rates of acute hepatitis B and vaccine doses per 100,000 population were visualized biannually from 2011 to 2018. Local indicators of spatial autocorrelation were used to detect county-level clustering. Significant differences in the median rate of acute hepatitis B pre and post intervention in counties receiving vaccine were evaluated using Wilcoxon signed-rank test and bootstrapping. A Bland-Altman graph visualized significant differences in county-level rates of acute hepatitis B before and after the WV Pilot Project compared to the statewide estimate. Analyses identified significant geographic clustering of acute hepatitis B in southern WV across all four time-periods. Nine of the $18(50 \%)$ counties receiving vaccine had significant declines in acute hepatitis B incidence compared to the statewide mean difference estimate. Findings suggest that increased dissemination of hepatitis B vaccine through local health departments and existing harm reduction services can reduce the incidence of acute hepatitis B in states such as WV, which have been disproportionately affected by substance misuse.
\end{abstract}

Keywords: Hepatitis B; Hepatitis B vaccine; Cluster analysis; Vaccine intervention 


\section{INTRODUCTION}

Hepatitis B is a liver disease resulting from infection with the hepatitis B virus (HBV).

Complications of infection include fulminant hepatitis, cirrhosis, liver failure, hepatocellular carcinoma, and death [1]. The virus is spread through contact with blood and body fluids, is highly infectious, and environmentally stable on hard surfaces for more than seven days [2]. In the United States, major risk factors for infection include sexual exposure and injection drug use $[3,4]$. People who inject drugs (PWID) are at an increased risk of acquiring hepatitis B infections through sharing of equipment to inject drugs and sexual contact [4, 5]. Estimates of the noninstitutionalized civilian United States population indicate that approximately 20 to $27 \%$ of PWID have lab markers consistent with past or present HBV infection compared to just $4.6 \%$ in the general population $[6,7]$.

Over the past three decades, the incidence of new HBV infections in the United States has declined $75 \%$ due to universal vaccination of infants at birth, catchup vaccinations of adolescents, and human immunodeficiency virus (HIV) prevention efforts in men who have sex with men and PWID [8-10]. However, the increase in substance misuse and injection drug use over the past decade has resulted in a resurgence of acute cases of hepatitis B among at-risk groups especially in parts of Appalachia [4, 11, 12]. Despite the decreasing trend nationwide, the rate of acute HBV infections in West Virginia (WV) has steadily increased since 2006. In 2016, WV's rate of acute HBV infections was 14.7 per 100,000 population, almost 15 times the national average of 1 per 100,000 population [10,13]. Appalachian states, in particular Kentucky, Tennessee, and West Virginia, have been disproportionately affected by opioid misuse [12]. From 2009 to 2013, the three states reported a 114\% increase in the number of reported acute hepatitis B cases [12]. The majority of these cases occurred in non-Hispanic whites, ages 30 to 39 , with $75 \%$ of all cases reporting injection drug use as a risk factor [12]. From 2012 to 2016, injection and non-injection drug use were the two most commonly reported risk factors among people with acute hepatitis B in WV $[13,14]$

The CDC's Advisory Committee on Immunization Practices (ACIP) currently recommends adults with risk factors, including recent or current injection drug use, receive hepatitis B vaccination as they may have reduced immunity or not completed all three doses of vaccine [4]. 
In January 2013, the West Virginia Bureau for Public Health, Office of Epidemiology and Prevention Services (WV OEPS) initiated the West Virginia Hepatitis B Vaccination Pilot Program (WV Pilot Project), part of a larger CDC funded HepB Vaccine Pilot Program implemented in 14 local and state health departments nationwide [15]. The goal of the two-year project in WV was to decrease the number of new HBV infections by providing over 10,000 doses of vaccine to at-risk adults in 18 counties with higher rates of acute hepatitis $B[12,16]$. Vaccine was administered to adults considered at-risk for HBV infection at sites where universal HBV vaccination is recommended including HIV clinics, local health department (LHD) STD clinics, and LHD community partnerships with local substance use treatment centers and correctional facilities [15-17].

The objectives of this study were to describe yearly changes in county-level acute hepatitis B incidence and assess the impact of the WV Pilot Project using geospatial methods.

\section{METHODS}

For this retrospective study, 2011-2018 acute hepatitis B data and the number of HBV vaccine doses provided to WV Pilot Project counties were obtained from WV OEPS. Acute hepatitis B case counts by county are the result of cases identified through the Nationally Notifiable Disease Surveillance System and were limited to those meeting the CDC's confirmed acute hepatitis B case definition; defined as "a case that meets the clinical case definition, is laboratory confirmed, and is not known to have chronic hepatitis B" [18]. Case data were incorporated into two-year estimated rates based on the years of vaccine distribution to counties participating in the WV Pilot Project; prior to vaccine distribution (2011-2012), during vaccine distribution (2013-2014 and 2015 -2016), and following vaccine distribution (2017-2018). Geospatial methods, including mapping and cluster analyses, were used to examine changes in the distribution of acute hepatitis $\mathrm{B}$ in WV in relation to vaccination efforts. County rates were estimated in ArcMap 10.5.1 (ESRI Redlands, CA) using mid-year U.S. Census population estimates and joined to a WV counties shape file $[19,20]$. Rate per 100,000 population of acute hepatitis B for each period were visualized using a quartile classification to highlight spread of the data, with darker colors indicating higher rates of acute hepatitis B. Vaccine doses per 100,000 population were calculated by dividing the total number of doses received by each county by their total 
population and multiplying by 100,000 . The resulting rates were visualized using graduated symbols, with larger symbols indicating greater distribution of vaccine doses.

Local Empirical Bayes Moran’s I and local indicators of spatial autocorrelation (LISA) maps were included to identify county-level acute hepatitis B clusters during each time-period using GeoDa 1.12 (GeoDa Center, AZ). To perform the cluster analyses, two-year case counts were set as the event variable, and midyear county-level census estimates were set as the base variable. A queen's contiguity weight was specified to maximize neighbors involved and cluster analyses results were permuted 99999 times to increase robustness of analyses and identify statistically significant areas of high county-level acute hepatitis B rates [21]. Statistical significance was assessed at the 0.05 alpha level. The null hypothesis for the local cluster analysis was a random pattern of county-level rates of acute hepatitis B with no local spatial association [22].

A Wilcoxon signed-rank test was used to detect a significant change in the median rate of acute hepatitis B per 100,000 population in WV Pilot Project counties before (2011-2014) and after (2015-2018) the intervention. Due to the small sample size of counties included in the analysis, bootstrapping was used to estimate the median rate change and $95 \%$ confidence interval, and to validate estimates from the Wilcoxon signed-rank test. A Bland-Altman graph, which plots the difference between two paired measurements against its mean, was used to visualize significant differences in county-level rates of acute hepatitis B per 100,000 population in all WV counties before and after the WV Pilot Project [23]. To assess statistical significance at the 0.05 alpha level, the statewide mean difference and corresponding 95\% confidence interval (CI) were plotted. Counties with differences in rates of acute hepatitis B outside the upper or lower bounds of the $95 \%$ CI were considered significant.

\section{RESULTS}

County-level rates of acute hepatitis B per 100,000 population and the rate of vaccine doses per 100,000 are displayed in Figure 1.1. Overall, rates of acute hepatitis B were highest in southern WV across the four time-periods. Zero case counts were present in 21 of 55 (38\%) WV counties in 2012-2013, decreasing to 10 of 55 (18\%) by 2017-2018. The highest rates of acute hepatitis B were observed in the southern counties, while the lowest rates were observed in northern counties. Over the four time-periods, progressive increases in rates of acute hepatitis B were observed in southern adjacent counties. Vaccine doses per 100,000 population ranged from 54.1 
to 4486.4 , and were limited to 18 counties based upon population size and rates of acute hepatitis B. The rate of vaccine doses per 100,000 indicates the magnitude of vaccine doses distributed in relation to the county population with higher rates indicating a larger proportion of the population potentially receiving vaccine.

County-level clustering in rates of acute hepatitis B in relation to vaccine doses per 100,000 population are displayed in Figure 1.2. Analysis of county-level clustering takes into account rates in adjacent counties and identifies definite hotspots and coldspots or groups of counties (cluster) with high or low rates of acute hepatitis B. While counties in clusters changed somewhat over each time period, in general, hotspots (high-high clusters) indicating statistically significant clustering of high county-level rates of acute hepatitis B, were detected in southern WV during all time-periods $(\mathrm{n}=7$ in 2011-2012, $\mathrm{n}=9$ in 2013-2014, $\mathrm{n}=9$ in 2015-2016, and $\mathrm{n}=8$ in 2017-2018). Over the four time-periods, the high-high clusters increased to include adjacent counties to the north and west, indicating progressive expansion into counties neighboring the initial multi-county hotspot. Of the nine counties identified in the 2013-2014 hotspot, seven (78\%) received vaccine doses. Cold spots (low-low clusters) indicating statistically significant clustering of low county-level rates of acute hepatitis B, were detected in northern and eastern WV counties during all time-periods $(n=10$ in 2011-2012, $n=9$ in 2013-2014, $n=10$ in 2015 2016, and $n=9$ in 2017-2018).

The median hepatitis B rate difference before and after the WV Pilot Project (calculated using the Wilcoxon signed-rank test and bootstrapping) for participating counties was an increase of 1.21 per 100,000 population $(95 \% \mathrm{CI},-13.29,21.93)$ following the intervention, however the increase was not significant ( $\mathrm{p}$-value $=0.90)$. Due to the small sample size of WV Pilot Project counties included in the analysis $(n=18)$, bootstrapping was used to estimate the median rate difference along with a $95 \%$ CI. This resulted in a median rate decrease of -4.16 of acute hepatitis B cases per 100,000 population $(95 \%$ CI, $-33.07,19.36)$ following the intervention. The Bland-Altman mean difference analysis found the statewide mean difference before and after the intervention was an increase of 10.80 cases per 100,000 population (95\% CI, 0.80, 20.79). County-level differences in rates of acute hepatitis B before and after the WV Pilot Project and the statewide mean difference and 95\% CI are displayed in Figure 1.3. Twelve of the $18 \mathrm{WV}$ Pilot Project counties (67\%) had a rate difference lower than the statewide estimate indicating a 
reduction in the rate of acute hepatitis B following vaccine distribution compared to the statewide mean difference. Of these, nine (50\%) had statistically significant declines as indicated by a rate difference below the lower bound of the statewide $95 \% \mathrm{CI}$. However, four (22\%) of the 18 WV Pilot Project counties had statistically significant increases in rates of acute hepatitis B following the intervention compared to the statewide mean difference. Of the 37 non-Pilot Project counties, $8(22 \%)$ experienced a statistically significant decrease and $11(30 \%)$ a statistically significant increase as indicated by values below and above the $95 \%$ CI respectively.

\section{DISCUSSION}

In this study, we found the incidence rate of acute hepatitis B increased steadily across WV with rates peaking in 2015-2016 and then slightly declining in 2017-2018. One of the most notable findings of this study was the shift in counties identified as hotspots through cluster analyses across the four time-periods. This shift suggests counties at risk for HBV transmission are changing and additional efforts are needed in emerging hotspots. Two counties identified as hotspots in all four time-periods did not receive vaccine through the WV Pilot Project demonstrating a missed opportunity to vaccinate at-risk individuals. All counties identified as a hotspot in the 2017-2018 cluster analysis may benefit from enhanced hepatitis B surveillance and increased efforts to prevent new HBV infections.

While the median difference calculated using both the Wilcoxon signed-rank test and bootstrapping estimates found non-statistically significant changes in the median rate of acute hepatitis B in Pilot Project counties, the median difference estimate obtained via bootstrapping indicates a decrease of 4.16 cases per 100,000 population (95\% CI, -33.07, 19.36) after WV Pilot Project implementation. Due to the small sample size of counties included in the analysis, the bootstrapping estimate most likely provides a better approximation compared to the estimate obtained from the Wilcoxon signed-rank test.

Another notable finding was the significant decrease in the rate difference before and after the WV Pilot Project (as indicated by values below the statewide mean difference $95 \% \mathrm{CI}$ ) in nine participating counties - Berkeley, Hancock, Harrison, Jefferson, Mason, McDowell, Mercer, Mingo, and Wyoming. While eight of the 37 (22\%) non-Pilot Project counties experienced a similar decrease, a significant decrease was observed in 50\% of WV Pilot Project counties. These findings indicate that the WV Pilot Project may have reduced the number of new HBV 
infections in at-risk adults especially in the southern part of WV where the greatest acute hepatitis B rate differences were observed. In total, 12 of the 18 WV Pilot Project counties had acute hepatitis B rate differences below the WV mean difference and while not all of the results were statistically significant, these findings point to the effectiveness of the WV Pilot Project in reducing or stabilizing rates in these counties.

From 2013 to 2015, the WV Pilot Project administered over 10,000 doses of HBV vaccine to adults considered at risk for HBV infection in 18 counties. At-risk adults were reached through local health department STD clinics, correctional facilities, substance use treatment centers, and HIV care facilities $[15,16]$. Completion of the three-dose series was cited as a challenge throughout the project [16]. In WV, of those who initiated the vaccine series, 59\% received the second dose, and 32\% completed the three-dose series [16]. Although some protection is conferred through receipt of one or two doses of hepatitis B vaccine, people who use drugs may have an altered immune response and therefore less likely to be protected after receiving just one or two doses [24]. Failure to complete the series, coupled with lower immune response may have resulted in less at-risk individuals protected against HBV infection, thus reducing the impact of the WV Pilot Project.

\section{Strength and Limitations}

Strengths of this study include the use of geospatial modeling, including cluster analyses, to examine trends in acute hepatitis B over eight years in WV. Hotspots identified in the cluster analyses indicate a statistically significant high county rate of acute hepatitis $B$ in relation to the surrounding counties representing a non-random pattern. Another strength is the use of bootstrapping, which provides a better approximation of the median pre and post intervention due to the small sample size of counties included in the estimation. Finally, the use of BlandAltman analysis to calculate and plot the difference in rates of acute hepatitis B before and after the WV Pilot Project for comparison with the statewide mean difference and 95\% CI, provides a method to assess if the rate differences for individual counties were statistically significant.

Potential limitations of this study include a lack of county-specific data regarding the number of participants who completed vaccination through the WV Pilot Project. However, vaccine doses per 100,000 population in each county is an indication of the volume of vaccine distributed in relation to the total population for that county. It is also unknown if people who initiated or 
completed the series developed immunity as post-serological testing was either not done or data were not available. Previous studies have shown that immune response to hepatitis B vaccine is lower in people with altered immune function including PWID, so not everyone vaccinated may have developed immunity [24]. Additionally, the 2018 acute hepatitis B case counts from WV OEPS used in all calculations were provisional and thus subject to change. Forty-four of the 55 WV counties have populations under 55,000 making the rates easily influenced by small case counts. Combined time-periods were used in order to stabilize rates, but small counties were still subject to large rates based on few cases of acute hepatitis B. Finally, many factors may have resulted in either an increase or decrease in the incidence rates of acute hepatitis B infections between the time-periods therefore making it difficult to determine the overall impact the WV Pilot Project on incidence rates. The first WV harm reduction program with syringe exchange opened in 2015 after the WV Pilot Project, and in 2017 there were 12 such programs [25].

Overall efforts to reduce the effects of substance misuse in WV may have reduced the number of new acute hepatitis B infections. However, to our knowledge there have been no new statewide hepatitis B vaccine initiatives since the WV Pilot Project.

\section{CONCLUSION}

Hepatitis B is a vaccine preventable disease, yet many at-risk adults remain unvaccinated and susceptible to infection. Ongoing harm reductions efforts, including syringe exchange programs, STD clinics, and LHD partnerships with community programs serving at-risk adults, should incorporate hepatitis B testing and vaccination to reduce the number of new HBV infections. Geographic information systems can guide surveillance efforts, placement of prevention services, and direct future interventions by identifying trends and changes in new HBV infections in WV. 


\section{LITERATURE CITED}

1. Ganem D, Prince AM. Hepatitis B virus infection—natural history and clinical consequences. N Engl J Med. 2004;350(11):1118-1129.

2. Than TT, Jo E, Todt D, et al. High environmental stability of hepatitis B virus and inactivation requirements for chemical biocides. J Infect Dis. 2019;219(7):1044-8.

3. Centers for Disease Controal and Prevention. Epidemiology and prevention of vaccinepreventable diseases. In: Hamborsky J, Kroger A, Wolfe S., eds. 13th ed. Washington D.C: Public Health Foundation; 2015.

4. Schillie S, Vellozzi C, Reingold A, et al. Prevention of hepatitis B virus infection in the United States: recommendations of the Advisory Committee on Immunization Practices. MMWR Recomm Rep. 2018;67(1):1.

5. Walsh N, Verster A, Rodolph M, Akl EA. WHO guidance on the prevention of viral hepatitis B and C among people who inject drugs. Int J Drug Policy. 2014;25(3):363-71.

6. Ioannou GN, 2011. Hepatitis B virus in the United States: infection, exposure, and immunity rates in a nationally representative survey. Ann Intern Med. 2011;154(5):319-328.

7. Shing JZ, Ly KN, Xing J, Teshale EH, Jiles RB. Prevalence of hepatitis B virus infection among US adults aged 20-59 years with a history of injection drug use: National Health and Nutrition Examination Survey, 2001-2016. Clin Infect Dis. ciz669, https://doi.org/10.1093/cid/ciz669

8. Van Buren RC, Schaffner W. Hepatitis B virus: a comprehensive strategy for eliminating transmission in the United States through universal childhood vaccination. Recommendations of the Immunization Practices Advisory Committee (ACIP). MMWR Recomm Rep. 1991;40:1-19.

9. Centers for Disease Control and Prevention. Update: Recommendations to prevent hepatitis B virus transmission--United States. MMWR Morb Mortal Wkly Rep. 1999;48(2):33.

10. Centers for Disease Control and Prevention. Surveillance for viral hepatitis - United States. Available at: https://www.cdc.gov/hepatitis/statistics/SurveillanceRpts.htm. Accessed January 15 2020.

11. Espinosa CM, Jhaveri R. Update on the management of hepatitis B and C infections in the neonatal period. Semin Perinatol. 2018;42(3):185-190.

12. Harris AM, Iqbal K, Schillie S, et al. Increases in acute hepatitis B virus infections Kentucky, Tennessee, and West Virginia, 2006-2013. MMWR Morb Mortal Wkly Rep. 2016;65(3):47-50.

13. Anil L, Simmons A. West Virginia viral hepatitis B and C surveillance 2012-2015. West Virginia Department of Health and Human Resources Bureau for Public Health. 2016. Available at: http://dhhr.wv.gov/oeps/disease/viral-hepatitis/documents/Hepatitis-Report-2016.pdf. Accessed February 22020. 
14. Division of Infectious Disease Epidemiology. Hepatitis B and hepatitis C infection in West Virginia - 2016 Surveillance Summary. West Virginia Department of Health and Human Resources Bureau for Public Health. 2018. Available at:

https://oeps.wv.gov/hepatitis/documents/data/Summary 2016 Acute HBV-HCV.pdf. Accessed February 32020.

15. Bridges CB, Watson TL, Nelson NP, et al. Challenges with hepatitis B vaccination of high risk adults-A pilot program. Vaccine. 2019;37(35):5111-5120.

16. West Virginia Office of Epidemiology and Prevention Services. Vaccination program aims to loosen the grip of hepatitis B on West Virginia. West Virginia EPI-Log. 2015;34(4):5-11. Available at: https://dhhr.wv.gov/oeps/Documents/EpiLog2015-4.pdf. Accessed February 3 2020.

17. Mast EE, Weinbaum CM, Fiore AE, et al. A Comprehensive immunization strategy to eliminate transmission of hepatitis B virus infection in the United States; recommendations of the Advisory Committee on Immunization Practices (ACIP); Immunization of adults; Part II. MMWR Recomm Rep. 2006;55(RR-16):1-33.

18. Centers for Disease Control and Prevention. National Notifiable Disease Surveillance System (NNDS). Hepatitis B, Acute 2012 Case Defintion. Available at: https://wwwn.cdc.gov/nndss/conditions/hepatitis-b-acute/case-definition/2012/. Accessed February 3, 2020.

19. U.S. Census Bureau Population Division. Annual Estimates of the Resident Population: April 1, 2010 to July 1, 2017. Generated from American FactFinder.

20. WV GIS Technical Center (2019). WV State GIS Data Clearninghouse. Retrieved from http://wvgis.wvu.edu/index.php.

21. Hendricks B, Mark-Carew M. Using exploratory data analysis to identify and predict patterns of human Lyme disease case clustering within a multistate region, 2010-2014. Spat Spatiotemporal Epidemiol. 2017;20:35-43.

22. Anselin L. Local indicators of spatial association-LISA. Geographical Analysis. 1995;27:93115 .

23. Giavarina D. Understanding Bland Altman analysis. Biochem Med (Zagreb). 2015;25(2):141-51.

24. Tran TQ, Grimes CZ, Lai D, Troisi CL, Hwang L. Effect of age and frequency of injections on immune response to hepatitis B vaccination in drug users. Vaccine. 2012;30(2):342-9.

25. West Virginia Department of Health and Human Resources Bureau for Public Health. White paper: the need for harm reducation programs in West Virginia. 2017. Available at:

https://oeps.wv.gov/harm reduction/documents/training/hrp white paper.pdf. Accessed February 2 2020. 
Figure 1.1 West Virginia county-level rates of acute hepatitis B from 2011 through 2018 and vaccine doses per 100,000 population. Darker colors and larger circles indicate a higher rate of acute hepatitis B and vaccine doses per 100,000 population respectively.

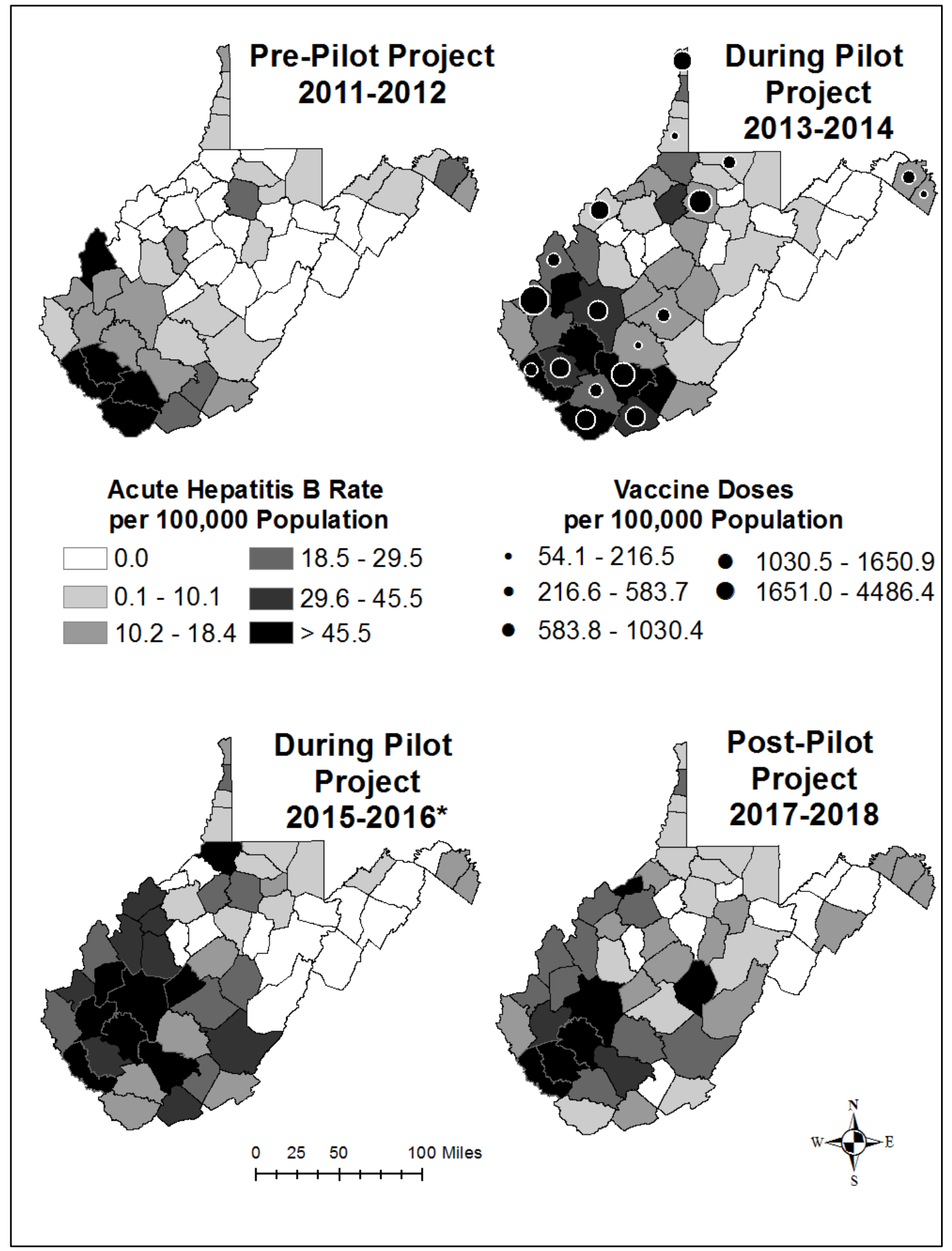

*The WV Pilot Project concluded in 2015 
Figure 1.2 West Virginia acute hepatitis B cluster analyses and vaccine doses per 100,000 population. High-high counties, depicted in black, are hotspots or a group of counties with high rates of acute hepatitis B. Low-low counties, depicted in dark grey, are coldspots or a group of counties with low rates of acute hepatitis B. High-low and low-high counties are spatial outliers indicating a county with a high rate surrounded by counties with low rates or a county with a low rate surrounded by counties with high rates of acute hepatitis B.

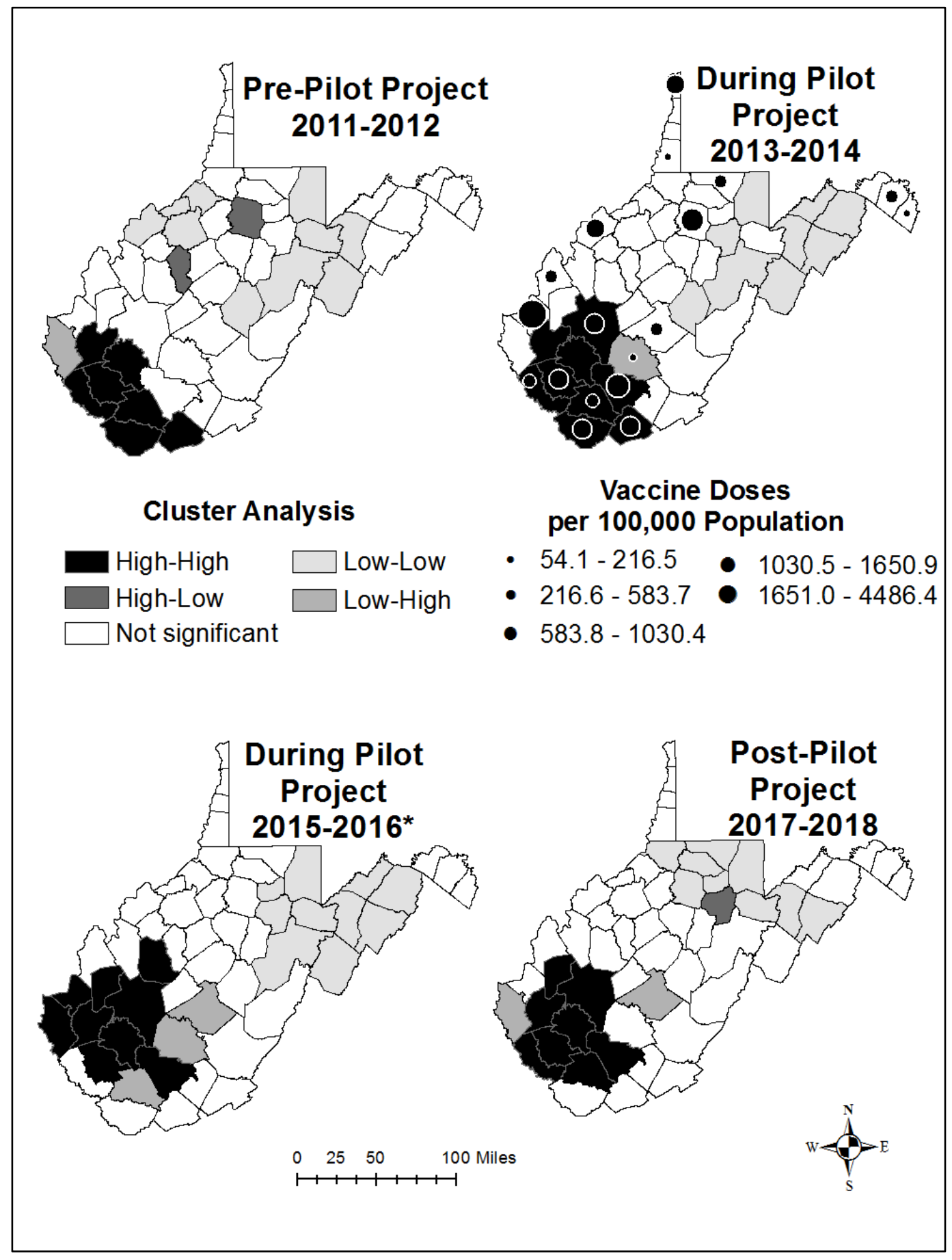

*The WV Pilot Project concluded in 2015 
Figure 1.3 Bland-Altman graph depicting the difference in acute hepatitis B rates per 100,000 population in WV Pilot Project and nonPilot Project counties compared to the mean difference for all of West Virginia before and after WV Pilot Project implementation. Values above or below the 95\% CI have statistically significant differences greater than or less than the mean difference for West Virginia.

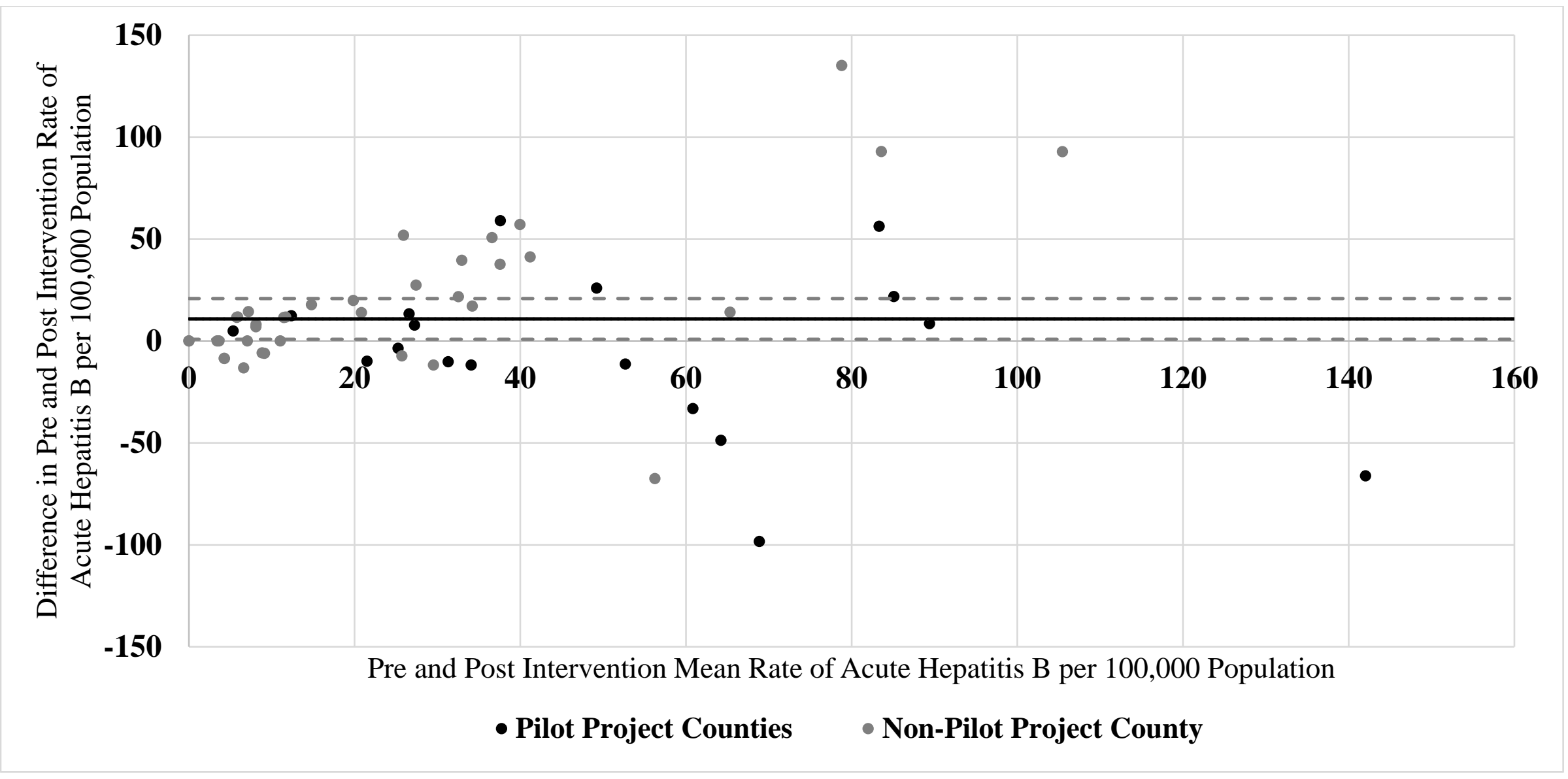




\title{
CHAPTER TWO
}

\section{Variations in Hepatitis B Vaccine Series Completion by Setting among \\ At-Risk Adults in West Virginia}

\begin{abstract}
Introduction: West Virginia (WV) leads the nation with the highest rate of acute hepatitis B. From 2013 to 2015, the West Virginia Hepatitis B Vaccination Pilot Project (WV Pilot Project) distributed over 10,000 doses of hepatitis B vaccine through local health department (LHD) clinics and through LHD outreach to correctional facilities and substance use treatment centers to at-risk adults. The objectives of this study were to determine which setting type was associated with the greatest likelihood of receiving all three or at least two doses of hepatitis B vaccine.
\end{abstract}

Methods: Data for this retrospective cohort study were accessed, extracted, and analyzed in 2019 from WV Pilot Project participant forms initially completed from 2013 to 2015. The odds of receiving all three or at least two doses were calculated using bivariate, multivariable, and mixed-effects regression models.

Results: Data were available for 1,201 participants. In multivariable logistic regression, participants vaccinated at substance use treatment centers (aOR: 1.37; 95\% CI: 1.01-1.86) and LHD family planning clinics (aOR: 3.74; 95\% CI: 1.98-7.06) were more likely to receive the three-dose series compared to those vaccinated at LHD STD clinics. For the secondary outcome, participants vaccinated through substance use treatment centers (aOR: 1.79; 95\% CI: 1.31-2.44), correctional facilities (aOR: 3.34; 95\% CI: 2.09-5.34), and LHD family planning clinics (aOR: 3.97; $95 \%$ CI: 1.72-9.16) were more likely to receive at least two doses.

Conclusion: Hepatitis B vaccination delivered at LHD family planning clinics, substance use treatment centers, or correctional facilities may increase vaccine dose completion in WV. 


\section{INTRODUCTION}

West Virginia (WV) has been disproportionately affected by the opioid crisis resulting in increased rates of acute hepatitis B [1-3]. For over a decade, WV's rate of acute hepatitis B has been the highest in the United States (U.S.) [1, 2]. In 2017, WV's rate was 11.7 per 100,000, almost 12 times higher than the national rate [1,2]. This increase in acute hepatitis B virus (HBV) infections is largely due to substance misuse, including injection drug use (IDU) [2, 3].

From 2012 to 2015, the Centers for Disease Control and Prevention (CDC) funded a vaccine pilot program in 14 state and local health departments, including $\mathrm{WV}$, to reduce the number of new HBV infections in at-risk adults [4]. Adults were vaccinated in settings where universal vaccination is recommended, and in specific settings where those with risk factors are typically seen or who were living in communities with an increased incidence of acute hepatitis B $[4,5]$. As part of the national pilot program, the West Virginia Hepatitis B Vaccination Pilot Program (WV Pilot Project) distributed over 10,000 doses of HBV vaccine to the 18 counties with higher rates of acute HBV [6]. Eighteen WV local health departments (LHDs) vaccinated at-risk adults in their own STD, family planning, vaccine, and other clinics as well as through expanded outreach to correctional facilities and substance use treatment centers through vaccine delivery partnerships.

The objectives of this study were to determine which setting type was associated with the greatest likelihood of receiving all three doses (primary objective) or at least two doses (secondary objective) of the three-dose HBV vaccine series among WV Pilot Project participants vaccinated through WV LHDs. Receipt of at least two doses of vaccine was chosen as the secondary objective for two reasons. First, some protective antibody response is conferred from receipt of just two doses of the standard 3-dose series, with approximately $75 \%$ of healthy adults 
achieving anti-HBs $\geq 10 \mathrm{mIU} / \mathrm{mL}$ after receiving two doses [5, 7, 8]. Second, in 2017, the FDA approved a new two-dose, HBV vaccine called Heplisav-B that can be completed in just four weeks compared to the minimum of 16 weeks needed to complete the traditional 3-dose series $[9,10]$. Therefore, understanding which sites were associated with completion of at least two doses of $\mathrm{HBV}$ vaccine has implications for future vaccination efforts using either the traditional 3-dose series or the new 2-dose Heplisav-B vaccine.

\section{METHODS}

Deidentified data for this retrospective cohort study were accessed in 2019 from LHDs that participated in the WV Pilot Project and extracted from available participant forms previously completed from January 2013 through September 2015. This study was approved by the West Virginia University Institutional Review Board.

Local health departments participating in the WV Pilot Project were contacted and invited to participate in the study. Participants were eligible for inclusion in the study if they received at least one dose of vaccine through the WV Pilot Project through a LHD; had not previously started the HBV vaccine series elsewhere; were negative for all HBV lab markers if tested; were not vaccinated at multiple settings; and had available data for both the main exposure variables and vaccine dosage administration. A flow chart detailing inclusion criteria for the final sample selection can be found in Figure 2.1. The three participating clinics serving persons with HIV were not included in this study.

\section{Outcome variables}

The outcome for the primary objective, completion of the three-dose HBV vaccine series, was defined as receiving all three doses at the appropriate dosing interval with at least four weeks 
between doses one and two, at least eight weeks between doses two and three, and a minimum of at least 16 weeks between doses one and three $[11,12]$. Non-completion for the primary outcome was defined as receiving one or two doses. The outcome for the secondary objective was defined as receiving two doses of the three-dose HBV vaccine series; non-completion was defined as receiving only one dose.

\section{Exposure variables}

The primary exposure variable, setting type, was restricted to the setting options available to LHDs on the participant form. These included STD and other clinics located at LHDs, and LHD outreach to correctional facilities and substance use treatment centers. Local health department 'other clinics' included participants vaccinated at any on-site LHD clinic other than the STD clinic. A separate 'LHD family planning' category was derived from the 'other clinics' category due to the number of participants who were vaccinated at this setting. Participants vaccinated through 'other clinics,' including family planning, were required to have a risk factor. However, people could state they did not wish to answer the risk factor information but would still like to be vaccinated against hepatitis B. Due to differences among LHDs in coding for correctional facilities and substance use centers, the two categories were standardized according to the following criteria: settings that included regional jails, drug courts, and day report centers were coded as 'correctional facility', and inpatient and outpatient drug treatment facilities, methadone and buprenorphine clinics were coded as 'substance use treatment center.' Additional exposure variables included sex, age, and race. Age was categorized as 18-29, 30-39, 40-49, and 50+ years old. Race was categorized as 'African American' or 'white/other/missing' due to the majority of participants identifying as 'white.' 


\section{Statistical analysis}

Analyses were completed in 2019. SAS version 9.4 was used for all analyses with $\alpha$ set to 0.05 . Missing data were treated with pairwise deletion. Frequencies and percentages were calculated for all exposure variables and both the primary and secondary outcomes. A Chi-squared test was used to assess for significant relationships between the exposure variables and the outcomes. Unadjusted odds ratios (uOR) with accompanying 95\% Confidence Intervals (CI) were calculated using bivariate logistic regressions with logit link and standard selection. Multivariable logistic regressions were used to calculate the adjusted odds ratios (aOR) with accompanying 95\% CIs for the main exposure variable and primary and secondary outcomes controlling for sex, age, and race. Mixed-effects generalized linear regression models (GLIMMIX) were used to account for the random effects of participants nested within LHDs. Exposure variables from the bivariate and multivariable models were included in the GLIMMIX models.

In this study, ORs are reported in lieu of risk ratios (RR) due to the convergence problems when estimating relative risk with the complex mixed-effects models. To assess for the possibility of the ORs overestimating the strength of association, a sensitivity analysis was conducted using unadjusted and adjusted RRs and accompanying 95\% CIs using generalized linear (GENMOD) models.

\section{RESULTS}

Eighteen LHDs received vaccine through the WV Pilot Project, of which 10 LHDs, representing counties from across the state, had participant forms available for inclusion in the study. A total of 1,428 at-risk adults received at least one dose of HBV vaccine through the WV Pilot Project. 
Of the 1,428 participants, 191 started the series at a location other than the LHD or were fully immunized per immunization records, 24 had lab results consistent with past or present HBV infection, and 12 were vaccinated at multiple sites or their forms could not be located. Overall, 1,201 participants met the inclusion criteria and were included in the analyses with the number of study eligible participants vaccinated through each LHD ranging from 26 to 441. (Figure $2.1 \&$ Supplementary Table 2.1).

A description of the number of participants vaccinated through each of the ten LHDs by setting type can be found in Supplementary Table 2.1. Nine LHDs vaccinated participants through their on-site STD clinics, eight vaccinated participants in 'other' on-site LHD clinics, and two vaccinated women through on-site LHD family planning clinics. Half of the LHDs vaccinated participants through partnerships with local substance use treatment centers and six collaborated with local correctional facilities.

The majority of participants were vaccinated through LHD STD clinics (46\%) or LHD outreach to substance use treatment centers $(27.6 \%)$ (Table 2.1$)$. Over half were male $(54.5 \%)$ and most self-identified their race as white $(85 \%)$. Approximately three-quarters of participants were between 18 and 39 years of age with almost equal numbers in the 18 to 29 (37\%) and 30 to 39 (36.7\%) age groups.

Thirty-six percent of participants received all three doses of the HBV vaccine series and 64.4\% received at least two doses (Supplementary Table 2.2). While the majority were vaccinated at LHD STD clinics (46\%), the highest percentage of three-dose completion occurred among those vaccinated at LHD family planning clinics (63.3\%) and through LHD outreach to substance use treatment centers $(41.6 \%)$. Additionally, the highest percentage of those receiving at least two 
doses were documented at LHD family planning clinics $(85.7 \%)$, correctional facilities (80.9\%), and substance use treatment centers $(72 \%)$.

\section{Primary and Secondary Objectives, Unadjusted}

For the primary objective, participants vaccinated at substance use treatment centers (uOR: 1.34; 95\% CI: 1.02-1.78) and LHD family planning clinics (uOR: 3.25; 95\% CI: 1.77-5.97) were significantly more likely to complete the three-dose HBV vaccine series compared to those vaccinated at LHD STD clinics (Table 2.2). Participants vaccinated through other LHD clinics (uOR: 0.53 ; 95\% CI: 0.34-0.82) were significantly less likely to receive three doses. Women (uOR: $1.43 ; 95 \%$ CI: 1.13-1.81) and participants ages 30 to 39 (uOR: 1.34; 95\% CI: 1.01-1.78), 40 to 49 (uOR: 2.13; 95\% CI: 1.48-3.08), and 50 and older (uOR: 2.21; 95\% CI: 1.50-3.24) were all significantly more likely to complete the three-dose series.

For the secondary objective, participants vaccinated at substance use treatment centers (uOR: 1.90; 95\% CI: 1.42-2.55), correctional facilities (uOR: 3.12; 95\% CI: 1.98-4.91), and LHD family planning clinics (uOR: 4.43; 95\% CI: 1.96-10.04) were all significantly more likely to receive at least two doses of $\mathrm{HBV}$ vaccine compared to those vaccinated at LHD STD clinics. Again, women (uOR: 1.37; 95\% CI: 1.08-1.75) were significantly more likely to receive at least two doses while participants self-identifying as African American (uOR: 0.82; 95\% CI: 0.690.98) were less likely to receive at least two doses.

\section{Primary and Secondary Objectives, Adjusted}

In the multivariable logistic regression model, after controlling for sex, age, and race, participants vaccinated at substance use treatment centers (aOR: 1.37; 95\% CI: 1.01-1.86) and LHD family planning clinics (aOR: 3.74; 95\% CI: 1.98-7.06) were more likely to complete the 
three-dose series while those vaccinated at other LHD clinics (aOR: 0.38; 95\% CI: 0.23-0.61) were significantly less likely to complete the three-dose series (Table 2.3). In this model, older age remained significantly associated with three-dose completion.

For the secondary outcome, participants vaccinated through substance use treatment centers (aOR: 1.79; 95\% CI: 1.31-2.44), correctional facilities (aOR: 3.34; 95\% CI: 2.09-5.34), and LHD family planning clinics (aOR: 3.97; 95\% CI: 1.72-9.16) were significantly more likely to receive at least two doses. Once again, women (aOR: 1.44; 95\% CI: 1.11-1.86) and participants ages 50 and older (aOR: 1.83; 95\% CI: 1.20-2.78) were also more likely to receive at least two doses in the full model.

Primary and Secondary Objectives, Adjusted and Controlling for LHD

In the mixed-effects model, after controlling for the LHD as a random effect and sex, age, and race as fixed effects, participants vaccinated at substance use treatment centers (aOR: 1.73; 95\% CI: $1.20-2.50)$ and LHD family planning clinics (aOR: 3.51; 95\% CI: 1.63-7.56) were significantly more likely to receive three doses compared to those vaccinated at LHD STD clinics (Supplementary Table 2.3). In this model, older age remained significantly associated with three-dose completion.

For the secondary objective, participants vaccinated at substance use treatment centers (aOR: 2.12; 95\% CI: 1.46-3.09), correctional facilities (aOR: 2.94; 95\% CI: 1.74-4.96), and LHD family planning clinics (aOR: 4.88; 95\% CI: 1.87-12.72) were significantly more likely to receive at least two doses of $\mathrm{HBV}$ vaccine. Women (aOR: 1.51; 95\% CI: 1.11-2.06) and participants ages 50 and older (aOR: 1.88; 95\% CI: 1.18-3.01) were also significantly more likely to receive at least two doses. 


\section{Sensitivity Analysis}

Unadjusted and adjusted RR estimates were compared with the calculated OR. In general, the OR closely approximated the RR. Given the OR and RR gave similar results that remained significant across both estimates, the OR were deemed an acceptable measure of association for this retrospective cohort study.

\section{DISCUSSION}

This is the first study to evaluate the impact of setting on completion of the HBV vaccine series among at-risk individuals vaccinated through WV LHDs, either at their own clinics or through expanded vaccine delivery partnerships in locations serving at-risk adults. In this study, we found LHD family planning clinics and LHD outreach to substance use treatment centers were associated with increased odds of receiving all three doses as well at least two doses of HBV vaccine compared to LHD STD clinics. Additionally, participants vaccinated through LHD outreach to correctional facilities were more likely to receive at least two doses. Differences in receiving either two or three doses between sites most likely reflects the vaccine delivery setting and the potential for continued future interactions with participants. People attending LHD STD clinics may only have a single visit, while women attending a family planning clinic are likely to return at least once a year or more. Substance use treatment centers and correctional facilities are also settings where clients are likely to have sustained interactions with program staff.

Both in WV and nationally the greatest number of participants were reached through STD clinics, but the proportion of participants receiving all three doses were low [4]. While STD clinics provide a way to initiate the HBV vaccine series in many at-risk adults, series completion remains a challenge in this setting. The use of electronic medical records and immunization 
information systems can potentially generate automatic reminders and flag client charts so staff can contact individuals for return visits to complete the vaccine series.

In 2016, the three most common risk factors among people with acute HBV infection in WV were injection drug use, street drug use, and incarceration [13]. The percentage of participants receiving at least two doses through LHD outreach at correctional facilities including drug court $(81 \%)$ and substance use treatment centers (72\%) indicates that ongoing LHD partnerships with these settings might facilitate their ability to reach more at-risk individuals who need hepatitis B vaccination due to a history of substance misuse or injection drug use. Harm reduction programs across the state also provide another venue to reach these high-risk individuals. LHDs manage the majority of harm reduction programs in WV: the first LHD syringe services program opened in late 2015 and as of 2020, 16 LHDs offer harm reduction services including testing for IDUrelated infections and HBV vaccination [14]. Given the risk factors for acute HBV infection in WV, targeting HBV vaccination efforts through substance use treatment centers, correctional facilities, and harm reduction programs, in conjunction with use of the new two-dose Heplisav-B vaccine, would provide protection to a greater number of those with the highest risk of hepatitis $\mathrm{B}$ in a shorter period.

A notable finding of this study is that women were significantly more likely to receive all three and just two doses compared to men. This, in combination with the increased odds of completion among family planning clinic participants, has important implications for preventing new hepatitis B infections in women of reproductive age. A recent study using national data from Quest Laboratories found a significant increase in the number of reproductive age women in WV testing positive for anti-HBc, a marker of past or current HBV infection [15]. Although the odds of completing the series were highest among LHD family planning clinic participants, the 
number of women reached was relatively small compared to other settings. Future vaccination efforts should include screening LHD family planning participants for hepatitis B risk factors. Women with risk factors, or those requesting STD screening as part of their family planning appointment, should be offered testing and vaccination.

Overall, completion of the second and third doses were higher in WV compared to other CDC awardees. In WV, of those who received the first dose, 59\% received the second dose, and $32 \%$ received all three doses [4]. Completion of the second and third doses for the six primarily urban CDC Pilot Program awardees with available data were $40 \%$ and $22 \%$ respectively [4]. The success of the WV Pilot Project may be due in part to the important role LHDs play in rural communities where healthcare access is limited. However, due to limited staff and associated vaccine/program costs, the WV LHDs were unable to sustain the WV Pilot Project activities after its conclusion in 2015. Expansion of Medicaid through the Affordable Care Act, along with the increased ability of LHDs to bill for services, may allow for provision of testing and HBV vaccination without additional cost to the client or LHDs in West Virginia.

\section{Potential limitations}

Both a strength and a limitation of this study is the inclusion of participant level data from ten of the 18 LHDs participating in the WV Pilot Project. The ten LHDs included counties from across the state, thus increasing the generalizability of findings; on the other hand, despite broad geographic representation, data were only available for $56 \%$ of the participating LHDs. Another potential limitation of this study is that data were not collected for research purposes, and the quality of the data varied among sites. To help overcome this limitation, settings where vaccine was administered were standardized across the LHDs, but there is still potential for misclassification bias. 


\section{CONCLUSION}

The WV Pilot Project provided over 10,000 doses of HBV vaccine to adults considered at risk of hepatitis B infection. Targeting vaccine delivery in settings outside of the LHD STD clinic may increase vaccine dose completion in $\mathrm{WV}$, thus resulting in more at-risk adults protected against HBV infection. Given that substance misuse and incarceration are the most common risk factors among people with acute HBV infection in WV, future LHD hepatitis B vaccine interventions should prioritize testing and vaccinating in settings serving high-risk adults including substance use treatment centers, correctional facilities, and harm reduction programs. 


\section{LITERATURE CITED}

1. Centers for Disease Control and Prevention. Surveillance for viral hepatitis - United States. Available at: https://www.cdc.gov/hepatitis/statistics/SurveillanceRpts.htm. Accessed January 152020.

2. Anil L, Simmons A. West Virginia viral hepatitis B and C surveillance 2012-2015. West Virginia Department of Health and Human Resources Bureau for Public Health. 2016. Available at: http://dhhr.wv.gov/oeps/disease/viral-hepatitis/documents/Hepatitis-Report2016.pdf. Accessed February 22020.

3. Harris AM, Iqbal K, Schillie S, et al. Increases in acute hepatitis B virus infections Kentucky, Tennessee, and West Virginia, 2006-2013. MMWR Morb Mortal Wkly Rep. 2016;65(3):47-50.

4. Bridges CB, Watson TL, Nelson NP, et al. Challenges with hepatitis B vaccination of high risk adults-A pilot program. Vaccine. 2019;37(35):5111-5120.

5. Mast EE, Weinbaum CM, Fiore AE, et al. A Comprehensive immunization strategy to eliminate transmission of hepatitis B virus infection in the United States; recommendations of the Advisory Committee on Immunization Practices (ACIP); Immunization of adults; Part II. MMWR Recomm Rep. 2006;55(RR-16):1-33.

6. West Virginia Office of Epidemiology and Prevention Services. Vaccination program aims to loosen the grip of hepatitis B on West Virginia. West Virginia EPI-Log. 2015;34(4):5-11. Available at: https://dhhr.wv.gov/oeps/Documents/EpiLog2015-4.pdf. Accessed February 3 2020.

7. André FE. Summary of safety and efficacy data on a yeast-derived hepatitis B vaccine. Am J Med. 1989;87(3):S14-20.

8. Zajac BA, West DJ, McAleer WJ, Scolnick EM. Overview of clinical studies with hepatitis B vaccine made by recombinant DNA. J Infect. 1986;13:39-45.

9. A two-dose hepatitis B vaccine for adults (Heplisav-B). JAMA. 2018;319(8):822-823.

10. Schillie S, Harris A, Link-Gelles R, et al. Recommendations of the Advisory Committee on Immunization Practices for use of a hepatitis B vaccine with a novel adjuvant. MMWR Morb Mortal Wkly Rep. 2018 Apr 20;67(15):455.

11. Immunization Action Coalition. Hepatitis A and hepatitis B vaccines: be sure your patients get the correct dose. 2019. Available at: https://www.immunize.org/technicallyspeaking/20161027.asp. Accessed April 9, 2020. 
12. Hamborsky J, Kroger A, Wolfe S, editors. Epidemiology and prevention of vaccinepreventable diseases. 13th ed. Washington DC: Public Health Foundation, 2015; 149-174.

13. Division of Infectious Disease Epidemiology. Hepatitis B and hepatitis C infection in West Virginia - 2016 surveillance summary. West Virginia Department of Health and Human Resources Bureau for Public Health. 2018. Available at:

https://oeps.wV.gov/hepatitis/documents/data/Summary_2016_Acute_HBV-HCV.pdf. Accessed February 32020.

14. West Virginia Office of Epidemiology and Prevention Services. West Virginia harm reduction programs at-a-glance. 2018. Available at:

https://oeps.wV.gov/harm_reduction/documents/about/wv_hrp.pdf. Accessed April 9, 2020.

15. Kushner T, Chen Z, Tressler S, et al. Trends in hepatitis B infection and immunity among women of childbearing age in the United States. Clin Infect Dis. 2019 Aug 26. doi: 10.1093/cid/ciz841. 
Figure 2.1. Flow chart of sample selection process

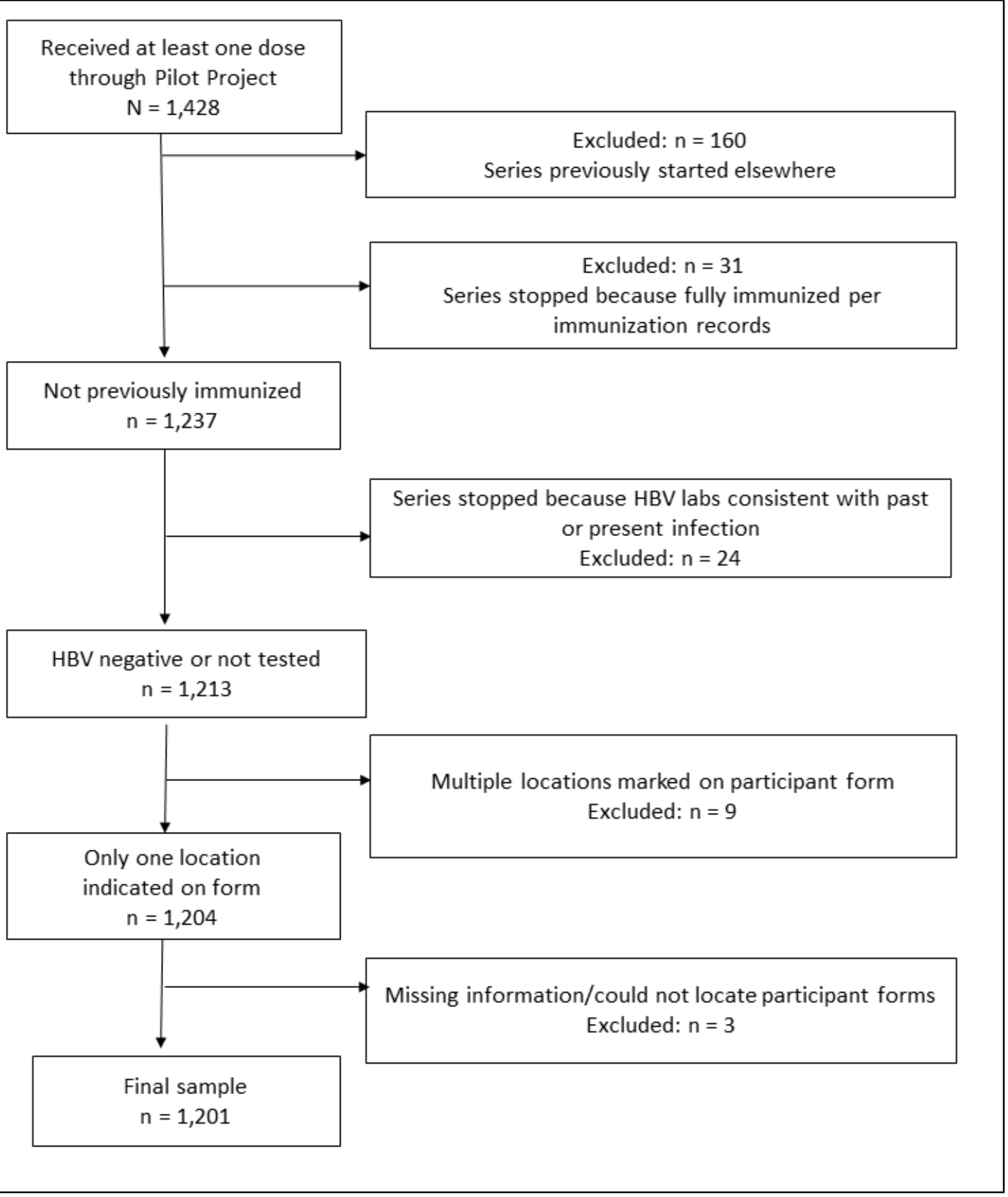


Table 2.1. Setting type and demographics of WV Pilot Project participants and primary and secondary outcomes

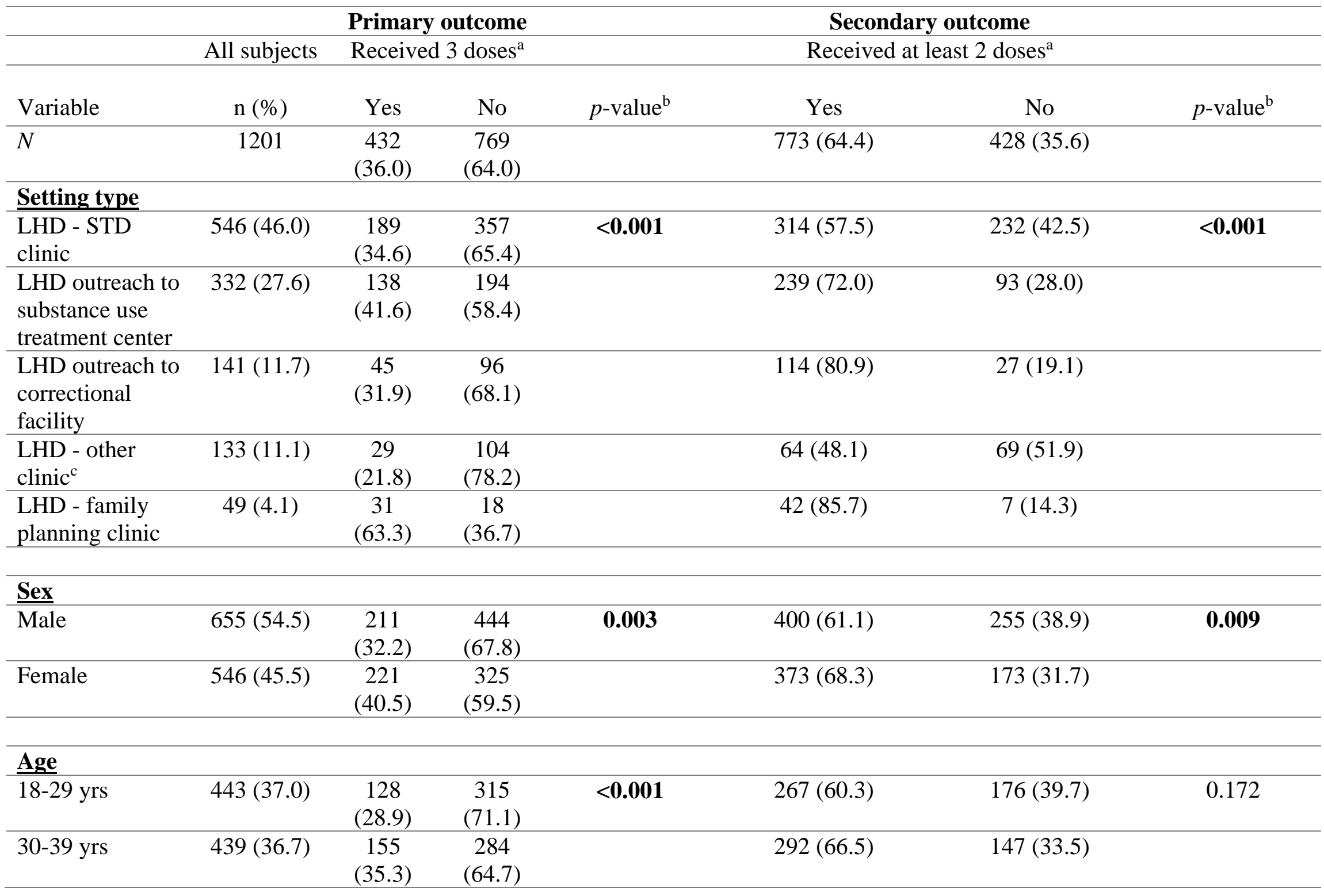




\begin{tabular}{lcccccc}
\hline $40-49$ yrs & $168(14.1)$ & $\begin{array}{c}78 \\
(46.4)\end{array}$ & $\begin{array}{c}90 \\
(53.6)\end{array}$ & $113(67.3)$ & $55(32.7)$ \\
\hline $50+$ & $146(12.1)$ & 69 & 77 & $97(66.4)$ & $49(33.6)$ \\
& $(47.3)$ & $(52.7)$ & & & \\
\hline & & & & $715(65.4)$ & $378(34.6)$ \\
\hline Race & & & 0.55 & $58(53.7)$ & $50(46.3)$ \\
\hline $\begin{array}{l}\text { White, missing, } \\
\text { \& other }\end{array}$ & $1093(91.0)$ & 396 & 697 & & $\mathbf{0 . 0 1 5}$ \\
\hline $\begin{array}{l}\text { African } \\
\text { American }\end{array}$ & $108(9.0)$ & $36.2)$ & $(63.8)$ & 72 & & \\
\hline
\end{tabular}

$2{ }^{a}$ Outcome variables are reported as the percentage relative to the row attribute

$3{ }^{\mathrm{b}} p$-value for Chi-squared test statistic. Abbreviations: STD =sexually transmitted disease; LHD = local health department

$4 \quad{ }^{\mathrm{c}}$ Includes participants vaccinated in LHD clinics other than STD and family planning

5 Note: Boldface indicates statistical significance $(\mathrm{p}<0.05)$. 
Table 2.2. Unadjusted odds ratios for exposure variables and primary and secondary objectives

\begin{tabular}{lcccccc}
\hline & \multicolumn{2}{c}{ Primary objective } & \multicolumn{3}{c}{ Secondary objective } \\
\hline & \multicolumn{3}{c}{ Received 3 doses } & \multicolumn{3}{c}{ Received at least 2 doses } \\
\hline Variable & uOR & $95 \%$ CI & p-value & uOR & $95 \%$ CI & $p$-value \\
\hline Setting type & & & & & & \\
\hline LHD - STD clinic & 1 & & & 1 & & \\
\hline $\begin{array}{l}\text { LHD outreach to substance } \\
\text { use treatment center }\end{array}$ & 1.34 & $(1.02-1.78)$ & $\mathbf{0 . 0 3 9}$ & 1.90 & $(1.42-2.55)$ & $<\mathbf{0 . 0 0 1}$ \\
$\begin{array}{l}\text { LHD outreach to } \\
\begin{array}{l}\text { correctional } \\
\text { facility }\end{array}\end{array}$ & 0.89 & $(0.60-1.32)$ & 0.547 & 3.12 & $(1.98-4.91)$ & $<\mathbf{0 . 0 0 1}$ \\
\hline $\begin{array}{l}\text { LHD - other clinic } \\
\text { LHD - family planning }\end{array}$ & 0.53 & $(0.34-0.82)$ & $\mathbf{0 . 0 0 5}$ & 0.69 & $(0.47-1.00)$ & 0.05 \\
clinic & 3.25 & $(1.77-5.97)$ & $\mathbf{< 0 . 0 0 1}$ & 4.43 & $(1.96-10.04)$ & $<\mathbf{0 . 0 0 1}$ \\
\hline
\end{tabular}

\begin{tabular}{lcccccc}
\hline$\underline{\text { Sex }}$ & & & & & & \\
\hline Male & 1 & & & 1 & & \\
\hline Female & 1.43 & $(1.13-1.81)$ & $\mathbf{0 . 0 0 3}$ & 1.37 & $(1.08-1.75)$ & $\mathbf{0 . 0 0 9}$ \\
\hline
\end{tabular}

\begin{tabular}{lcccccc}
\hline Age & 1 & & & 1 & & \\
\hline $18-29 \mathrm{yrs}$ & 1.34 & $(1.01-1.78)$ & $\mathbf{0 . 0 4 2}$ & 1.31 & $(1.00-1.72)$ & 0.055 \\
\hline $30-39 \mathrm{yrs}$ & 2.13 & $(1.48-3.08)$ & $<\mathbf{0 . 0 0 1}$ & 1.35 & $(0.93-1.97)$ & 0.112 \\
\hline $40-49 \mathrm{yrs}$ & 2.21 & $(1.50-3.24)$ & $<\mathbf{0 . 0 0 1}$ & 1.31 & $(0.88-1.93)$ & 0.184 \\
\hline $50+$ & & & & & & \\
\hline
\end{tabular}

\section{$\underline{\text { Race }}$}

\begin{tabular}{lcccccc}
\hline White, missing, \& other & 1 & & & 1 & & \\
\hline African American & 0.88 & $(0.58-1.34)$ & 0.549 & 0.61 & $(0.41-0.91)$ & 0.016 \\
\hline
\end{tabular}

Abbreviations: STD =sexually transmitted disease; LHD = local health department.

${ }^{\text {a }}$ Includes participants vaccinated in LHD clinics other than STD and family planning

Note: Boldface indicates statistical significance $(\mathrm{p}<0.05)$. 
Table 2.3. Adjusted odds ratios for exposure variables and primary and secondary objectives

\begin{tabular}{|c|c|c|c|c|c|c|}
\hline & \multicolumn{3}{|c|}{ Primary outcome } & \multicolumn{3}{|c|}{ Secondary outcome } \\
\hline & \multicolumn{3}{|c|}{ Received 3 doses } & \multicolumn{3}{|c|}{ Received at least 2 doses } \\
\hline Variable & $\mathrm{aOR}$ & $95 \% \mathrm{CI}$ & $p$-value & $\mathrm{aOR}$ & $95 \% \mathrm{CI}$ & $p$-value \\
\hline \multicolumn{7}{|l|}{ Setting type } \\
\hline$\overline{\text { LHD - STD clinic }}$ & 1 & & & 1 & & \\
\hline $\begin{array}{l}\text { LHD outreach to } \\
\text { substance use treatment } \\
\text { center }\end{array}$ & 1.37 & $(1.01-1.86)$ & 0.041 & 1.79 & $(1.31-2.44)$ & $<0.001$ \\
\hline $\begin{array}{l}\text { LHD outreach to } \\
\text { correctional } \\
\text { facility }\end{array}$ & 0.91 & $(0.60-1.39)$ & 0.6622 & 3.34 & $(2.09-5.34)$ & $<0.001$ \\
\hline LHD - other clinic ${ }^{\mathrm{a}}$ & 0.38 & $(0.23-0.61)$ & $<0.001$ & 0.58 & $(0.39-0.87)$ & 0.008 \\
\hline $\begin{array}{l}\text { LHD - family planning } \\
\text { clinic }\end{array}$ & 3.74 & $(1.98-7.06)$ & $<0.001$ & 3.97 & $(1.72-9.16)$ & 0.001 \\
\hline
\end{tabular}

\begin{tabular}{|c|c|c|c|c|c|c|}
\hline \multicolumn{7}{|l|}{$\underline{\operatorname{Sex}}$} \\
\hline Male & 1 & & & 1 & & \\
\hline Female & 1.28 & $(0.98-1.66)$ & 0.069 & 1.44 & $(1.11-1.86)$ & 0.006 \\
\hline
\end{tabular}

\begin{tabular}{lcccccc}
\hline Age & & & & & & \\
\hline $18-29 \mathrm{yrs}$ & 1 & & & 1 & & \\
\hline $30-39 \mathrm{yrs}$ & 1.40 & $(1.04-1.89)$ & $\mathbf{0 . 0 2 7}$ & 1.21 & $(0.91-1.62)$ & 0.196 \\
\hline $40-49 \mathrm{yrs}$ & 2.57 & $(1.76-3.77)$ & $<\mathbf{0 . 0 0 1}$ & 1.39 & $(0.94-2.05)$ & 0.102 \\
\hline $50+$ & 3.38 & $(2.23-5.13)$ & $<\mathbf{0 . 0 0 1}$ & 1.83 & $(1.20-2.78)$ & $\mathbf{0 . 0 0 5}$ \\
\hline
\end{tabular}

\begin{tabular}{lcccccc}
\hline Race & & & & & & \\
\hline White, missing, \& other & 1 & & & & & \\
\hline African American & 0.92 & $(0.59-1.44)$ & 0.729 & 0.78 & $(0.52-1.19)$ & 0.254 \\
\hline
\end{tabular}

Abbreviations: STD =sexually transmitted disease; LHD = local health department.

${ }^{a}$ Includes participants vaccinated in LHD clinics other than STD and family planning

Note: Boldface indicates statistical significance $(\mathrm{p}<0.05)$. 
Supplementary Table 2.1. Number of WV Pilot Project participants vaccinated through each local health department by setting type

\begin{tabular}{lllllll}
\hline \multicolumn{7}{c}{ Setting type } \\
\hline $\begin{array}{l}\text { Local Health } \\
\text { Department }\end{array}$ & $\begin{array}{l}\text { LHD - STD } \\
\text { clinic }\end{array}$ & $\begin{array}{l}\text { LHD outreach } \\
\text { to substance } \\
\text { use treatment } \\
\text { centers }\end{array}$ & $\begin{array}{l}\text { LHD } \\
\text { outreach to } \\
\text { correctional } \\
\text { facilities }\end{array}$ & $\begin{array}{l}\text { LHD } \\
\text { other } \\
\text { clinic }\end{array}$ & $\begin{array}{l}\text { LHD - } \\
\text { family } \\
\text { planning } \\
\text { clinic }\end{array}$ & $\begin{array}{l}\text { Total } \\
\text { participants }\end{array}$ \\
\hline 1 & 194 & 157 & 90 & - & - & 441 \\
\hline 2 & 86 & 60 & - & 36 & 6 & 188 \\
\hline 3 & 74 & 21 & 6 & - & 43 & 144 \\
\hline 4 & 21 & 71 & 11 & 4 & - & 107 \\
\hline 5 & 63 & - & 10 & 5 & - & 78 \\
\hline 6 & 22 & - & 7 & 39 & - & 68 \\
\hline 7 & 35 & - & 17 & 16 & - & 68 \\
\hline 8 & - & 23 & - & 24 & - & 47 \\
\hline 9 & 27 & - & - & 7 & - & 34 \\
\hline 10 & 24 & - & - & 2 & - & 26 \\
\hline Total participants & 546 & 332 & 141 & 133 & 49 & 1201 \\
\hline Total setting type & 9 & 5 & 6 & 8 & 2 & \\
\hline a Includes participants vaccinated in LHD clinics other than STD and family planning &
\end{tabular}

Supplementary Table 2.2. Frequency and percentage of doses received by WV Pilot Project setting type

\begin{tabular}{|c|c|c|c|}
\hline Setting type & 1 dose & $\begin{array}{c}2 \text { doses* } \\
\text { n }(\%)\end{array}$ & $\begin{array}{l}3 \text { doses*** } \\
\text { n }(\%)\end{array}$ \\
\hline LHD - STD clinic $(n=9)$ & 546 & $314(57.5)$ & $189(34.6)$ \\
\hline $\begin{array}{l}\text { LHD outreach to substance use } \\
\text { treatment center }(n=5)\end{array}$ & 332 & $239(72.0)$ & $138(41.6)$ \\
\hline $\begin{array}{l}\text { LHD outreach to correctional } \\
\text { facility }(n=6)\end{array}$ & 141 & $114(80.9)$ & 45 (31.9) \\
\hline LHD - other clinic ${ }^{\mathrm{a}}(\mathrm{n}=8)$ & 133 & $64(48.1)$ & $29(21.8)$ \\
\hline LHD - family planning clinic $(n=2)$ & 49 & $42(85.7)$ & $31(63.3)$ \\
\hline Total participants & 1201 & $773(64.4)$ & $432(36.0)$ \\
\hline
\end{tabular}

*Those receiving dose one who received dose two, **those receiving dose one who received dose three. Abbreviations: STD =sexually transmitted disease; LHD = local health department.

${ }^{a}$ Includes participants vaccinated in LHD clinics other than STD and family planning 
Supplementary Table 2.3. Mixed-effects model adjusted odds ratios controlling for local health department as a random effect

\begin{tabular}{lcccccc}
\hline & \multicolumn{2}{c}{ Primary outcome } & \multicolumn{3}{c}{ Secondary outcome } \\
\hline & \multicolumn{2}{c}{ Received 3 doses } & \multicolumn{3}{c}{ Received at least 2 doses } \\
\hline Variable & aOR & $95 \%$ CI & $p$-value & aOR & $95 \%$ CI & $p$-value \\
\hline Setting type & & & & & & \\
\hline LHD - STD clinic & 1 & & & & & \\
\hline $\begin{array}{l}\text { LHD outreach to } \\
\text { substance use treatment } \\
\text { center }\end{array}$ & 1.73 & $(1.20-2.50)$ & $\mathbf{0 . 0 0 6}$ & 2.12 & $(1.46-3.09)$ & $<\mathbf{0 . 0 0 1}$ \\
\hline $\begin{array}{l}\text { LHD outreach to } \\
\begin{array}{l}\text { correctional } \\
\text { facility }\end{array}\end{array}$ & 0.93 & $(0.57-1.50)$ & 0.737 & 2.94 & $(1.74-4.96)$ & $<\mathbf{0 . 0 0 1}$ \\
\hline LHD - other clinic & 0.56 & $(0.30-1.01)$ & 0.054 & 0.74 & $(0.44-1.23)$ & 0.221 \\
\hline $\begin{array}{l}\text { LHD - family planning } \\
\text { clinic }\end{array}$ & 3.51 & $(1.63-7.56)$ & $\mathbf{0 . 0 0 3}$ & 4.88 & $(1.87-12.72)$ & $\mathbf{0 . 0 0 3}$ \\
\hline
\end{tabular}

\begin{tabular}{lcccccc}
\hline Sex & \multicolumn{1}{l}{ Male } & 1 & & & & \\
\hline Female & 1.32 & $(0.97-1.81)$ & 0.075 & 1.51 & $(1.11-2.06)$ & $\mathbf{0 . 0 1 4}$ \\
\hline & & & & & & \\
\hline$\underline{\text { Age }}$ & 1 & & & & & \\
\hline $18-29$ yrs & 1.50 & $(1.09-2.07)$ & $\mathbf{0 . 0 1 5}$ & 1.31 & $(0.96-1.79)$ & 0.086 \\
\hline $30-39$ yrs & 2.64 & $(1.74-4.00)$ & $<\mathbf{0 . 0 0 1}$ & 1.45 & $(0.95-2.22)$ & 0.084 \\
\hline $40-49$ yrs & 3.23 & $(2.03-5.14)$ & $<\mathbf{0 . 0 0 1}$ & 1.88 & $(1.18-3.01)$ & $\mathbf{0 . 0 1}$ \\
\hline $50+$ & & & & & & \\
\hline
\end{tabular}

\section{$\underline{\text { Race }}$}

\begin{tabular}{lcccccc}
\hline White, missing, \& other & 1 & & & 1 & & \\
\hline African American & 1.01 & $(0.63-1.61)$ & 0.971 & 0.82 & $(0.53-1.28)$ & 0.389
\end{tabular}

Abbreviations: STD =sexually transmitted disease; LHD = local health department.

${ }^{a}$ Includes participants vaccinated in LHD clinics other than STD and family planning

Note: Boldface indicates statistical significance $(\mathrm{p}<0.05)$. 


\section{CHAPTER THREE}

Factors Associated with Hepatitis B Exposure among People who Report Using

Methamphetamine: NHANES 2009-2016

Tressler SR, Kushner T, Bhandari R. Factors Associated With Hepatitis B Exposure Among People Who Report Using Methamphetamine: National Health and Nutrition Examination Survey 2009-2016, J Infect Dis 2020; 221(2):243-250.

\section{ABSTRACT}

Background: With the nation's focus on the opioid crisis, methamphetamine has made a comeback, potentially increasing risk for hepatitis B. We examined factors associated with hepatitis B virus (HBV) exposure among people who reported ever using methamphetamine in a nationally representative survey.

Methods: We utilized the National Health and Nutrition Examination Survey to examine factors associated with HBV exposure among participants who reported ever using methamphetamine using bivariate and multivariable logistic regression.

Results: Overall, 847 participants met the study inclusion criteria. In multivariable logistic regression, female sex (aOR 3.83, 95\% CI 1.65 - 8.90), living below the poverty threshold (aOR 3.17, $95 \%$ CI 1.39 - 7.21), injection drug use (IDU) (aOR 4.89, 95\% CI 1.95 - 12.26), active hepatitis $\mathrm{C}(\mathrm{HCV})$ infection (aOR 3.39, 95\% CI 1.10 - 12.26), and identifying as men who have sex with men (aOR 28.21, 95\% CI 5.19 - 153.38) were significantly associated with HBV exposure.

Conclusions: The odds of HBV exposure for females who reported using methamphetamine was four times higher than males. Poverty, IDU, and HCV infection were also associated. As methamphetamine use increases, it is critical to identify those at risk of acquiring HBV infections in order to target testing and vaccination.

Keywords: Methamphetamine; hepatitis B; NHANES 


\section{INTRODUCTION}

Hepatitis B is a significant public health problem worldwide with over 350 million chronic carriers globally, and an estimated 850,000 to 2.2 million individuals in the U.S. [1-3]. Although the leading cause of chronic infection worldwide is through vertical transmission, in the U.S., the most common mode of transmission is horizontal. Hepatitis B virus (HBV) is spread through contact with blood and body fluids and is highly infectious. Acute infection can progress to lifelong chronic infection with younger age at time of transmission being the greatest factor in progression to chronicity [4]. About $50 \%$ of people chronically infected are unaware of their infection and remain a source of ongoing transmission [5].

In the U.S., the incidence of acute hepatitis B infections has decreased $75 \%$ over the past three decades largely due to the implementation of universal vaccination of infants at birth in 1991 and the recommendation for catch-up vaccination of adolescents in 1997 [6, 7]. Due in part to low rates of hepatitis $\mathrm{B}$ nationwide, attention has centered on transmission and prevention of HIV and HCV in high-risk groups. As recently as 2006, the rate of acute HBV infections in the U.S. has remained stable at around 1 case per 100,000 people [8]. However, over the past decade, opioid misuse and injection drug use (IDU) has resulted in a resurgence in cases of acute hepatitis B $[9,10]$.

Nationwide, in 2015 the highest incidence of acute HBV infections occurred among persons 30 to 39 years of age with $30 \%$ of newly infected people reporting IDU as a risk factor [11]. Most notably, there was a substantial increase in acute HBV cases in parts of Appalachia including Kentucky, Tennessee, and West Virginia. From 2009-2013, there was a 114\% increase in the number of newly reported acute infections in these three states [8]. The majority of the cases occurred among non-Hispanic whites, 30 to 39 years of age with $75 \%$ reporting IDU as a risk factor [8].

With the nation's focus on the opioid crisis, methamphetamine has made a largely unnoticed comeback. Methamphetamine use in the U.S. peaked around 2005 but has reemerged as a threat in recent years accounting for $11 \%$ of overdose deaths in 2016 [12, 13]. Nationwide use has increased along with reported co-use with opioids [12]. A recent study found methamphetamine 
use almost doubled from $18.8 \%$ in 2011 to $34.2 \%$ among people using opioids who sought treatment in the U.S. in 2017 [14]. The increase in methamphetamine use and co-use with opioids represents a public health threat requiring a refocusing of response efforts.

Methamphetamine is a potent stimulant that can be smoked, injected, snorted, or taken orally [15]. People who use methamphetamine either through injection or non-injection routes are at an increased risk for acquiring sexually transmitted infections including hepatitis B [15]. For people who inject methamphetamine, HBV can be acquired through sharing of needles as well as injecting equipment, and sexual practices. Outbreaks of hepatitis B among people who inject methamphetamine have been documented [16, 17]. A study by Vogt et al. (2006) found an association between sharing equipment used to inject methamphetamine, including rinse water and cotton filters, and HBV infection [16]. More recently, methamphetamine has been implicated in a ten-fold increase in acute hepatitis B cases, as well as an increase in hepatitis C, HIV, and syphilis in Winnipeg, Canada [18].

Hepatitis B remains a real and ongoing threat to a number of high-risk groups, including people who use drugs and those engaging in high-risk sexual behaviors. It is recommended that highrisk people without serological evidence of HBV infection or immunity be vaccinated against HBV [10]. As methamphetamine use and co-use with opioids increase, it is important to understand the risk factors associated with HBV exposure among this population to help guide education, testing, and vaccination efforts.

In this study, we examined factors associated with hepatitis B exposure among people who reported ever using methamphetamine in the National Health and Nutrition Examination Survey (NHANES) [19].

\section{METHODS}

The study population included NHANES participants who answered "yes" to ever using cocaine/heroin/methamphetamine, and subsequently "yes" to using methamphetamine from 2009 to 2016 and completed testing for HBV. Participants under the age of 18 and older than 69 were not eligible to answer this question and were excluded from this study. Participants with serological evidence of HBV immunity from vaccination were also excluded from the study (see Figure 3.1). 


\section{Study design}

NHANES is a cross-sectional survey conducted by the Centers for Disease Control and Prevention's (CDC) National Center for Health Statistics (NCHS) to assess health and nutritional status of the U.S. population [19]. Data are collected over a two-year period and include participant interviews accompanied by physical examinations and laboratory specimen collection. Participants are selected using a complex, multistage, probability sampling design that is representative of U.S. noninstitutionalized civilian population living in the 50 states and the District of Columbia. NHANES data are publicly available for research purposes.

\section{Outcome variable}

The outcome variable, exposure to $\mathrm{HBV}$, was defined as a positive result to total hepatitis B core antibody (anti-HBc), a marker of past or present infection with hepatitis B. Susceptibility to HBV was defined as being negative for all HBV lab markers including anti-HBc, hepatitis B surface antigen (HBsAg), and hepatitis B surface antibody (HBsAb). Participants with serological evidence of vaccine-induced immunity, defined as being solely HBsAb positive, were excluded.

\section{Exposure variables}

Exposure variables known to be associated with hepatitis B exposure were chosen based on previous studies and availability in the NHANES dataset. For the frequency of methamphetamine use and questions on sexual identity and partners, only participants 18 to 59 years old were eligible to answer. Classifications for each variable can be found in Table 3.1. Hepatitis C status was coded as positive, negative, or missing. Negative was defined as antibody negative, or antibody positive but subsequently testing RNA negative. Positive was defined as confirmed to be RNA positive after a positive antibody test indicating an active HCV infection. Lab markers for HIV, HSV 2, and syphilis were not included due to small sample size and inability to combine due to differences in age groups tested. Indeterminate lab results were coded as missing.

\section{Data analysis}


SAS version 9.4 was used for all analyses. Survey procedures including SURVEYFREQ and SURVEYLOGISTIC were used to account for complex survey design in the analysis.

SDMVSTRA was used in the strata statements and SDMVPSU in the cluster statements.

Weighted frequencies and standard errors for the combined eight years of data were calculated by multiplying the sample weight WTMEC2YR by 1/4. A subcategory including only participants who completed the medical exam and answered 'yes' to ever using methamphetamine was included at the beginning of each table statement when calculating frequencies and in the domain statement for logistic regression. For all analyses, confidence intervals (CI) that did not cross one and a $p$-value less than .05 were considered statistically significant.

Descriptive statistics, weighted percentages, and weighted frequencies were calculated for all variables. The Rao Scott Chi-squared statistic was calculated to assess the relationship between each exposure variable and HBV exposure. Bivariate logistic regression was used to calculate the unadjusted odds ratio (uOR) and 95\% CI for each exposure variable and HBV exposure. Three multivariable logistic regression models were used to calculate the adjusted odds ratios (aOR) and $95 \% \mathrm{CI}$ for the exposure variables and HBV exposure. Model 1 examined the association of demographic variables (sex, age, and race/ethnicity) with the outcome among participants 18-69 years. Model 2 built on Model 1 and examined the association of poverty index, health insurance, IDU, and HCV status in addition to the demographic variables in Model 1 among participants 18-69 years. Model 3 adjusted for all exposure variables but only included participants 20 to 59 years old due to age restriction for answering the following questions: education (20 years and older), number of times used methamphetamine (18 to 59 years old), sexual identity (18 to 59 years old), and number of sex partners in the past year (18 to 59 years old). A missing category was created for each exposure variable with missing data and was included in the analyses.

A sensitivity analysis was performed on missing values for question DUQ240 - Have you ever used cocaine/heroin/methamphetamine - to examine differences in missing data by sex, age, and race/ethnicity.

\section{RESULTS}


A total of 40,439 people participated in NHANES from 2009 through 2016. Out of the total participants who reported ever using methamphetamine and completed HBV testing, 5.6\% were exposed to $\mathrm{HBV}, 15.1 \%$ had vaccine-induced immunity, and almost $80 \%$ were susceptible to $\mathrm{HBV}$ infection. Of those exposed to $\mathrm{HBV}, 6.4 \%$ were $\mathrm{HBsAg}$ positive indicating an active hepatitis B infection. After excluding those with vaccine-induced immunity, $6.6 \%$ of participants who reported ever using methamphetamine had lab markers consistent with HBV exposure and 93.4\% were susceptible to HBV infection. Overall, 847 participants reported ever using methamphetamine and were either exposed or susceptible to hepatitis B and thus eligible for inclusion in the study (see Figure 3.1).

Frequencies and weighted estimates for exposure variables and the HBV exposure can be found in Table 3.1. Based on the weighted estimate, the 847 participants represented approximately $11,048,115$ people in the U.S. All reported percent estimates and standard errors are calculated from the weighted frequencies.

In the study sample, the majority of participants were male (68.3\%) and approximately, threequarters of participants were between 30 to 59 years of age, with the greatest proportion in the 50 to 59 age range $(30.8 \%)$. Most participants were non-Hispanic white $(77.5 \%)$ and living at or above twice the poverty index $(58.6 \%)$. While only $15 \%$ of participants were categorized as living below the poverty index threshold, they comprised over one-third of those exposed to HBV (35.4\%). Nearly three-quarters of participants reported having some type of health insurance $(73.1 \%)$ and education attainment as high school, GED, or higher. About a fifth reported ever injecting drugs $(20.2 \%)$ but they accounted for over half of those exposed to HBV (56.7\%). While only $7 \%$ had an active HCV infection they accounted for $28.5 \%$ of those exposed to HBV. Almost an equal number of participants reported using methamphetamine $\leq$ to 5 times, 6 to 49 times, and $\geq 50$ times. Of those exposed to HBV $42.5 \%$ reported using methamphetamine $\geq 50$ times. The majority of participants self-identified as heterosexual (80.7\%) and reported less than 2 sexual partners in the past year $(65.8 \%)$.

Table 3.2 presents the unadjusted odds ratios (uOR) and 95\% CIs for each exposure variable and the outcome variable. Among those who reported using methamphetamine, being female was significantly associated with exposure to HBV (uOR 2.11, 95\% CI 1.05 - 4.26), as was being non-Hispanic black (uOR 2.63, 95\% CI 1.30 - 5.3), living below the poverty threshold (uOR 
3.73, 95\% CI 1.93 - 7.21), IDU (uOR 6.28, 95\% CI 2.77- 14.26), active HCV infection (uOR 7.07, 95\% CI 3.24 - 15.44), using methamphetamine $\geq 50$ times (5.01, 95\% CI 1.88 - 13.35), and identifying as MSM (uOR 6.33, 95\% CI $1.81-22.14)$.

Adjusted odds ratios (aOR) and 95\% CIs were calculated in models 1, 2, and 3. The results of each model can be found in Table 3.2. After controlling for sex, age, and race/ethnicity in model 1, being female (aOR 2.18, 95\% CI $1.06-4.51$ ) and non-Hispanic black (aOR 2.37, 95\% CI $1.09-2.31$ ) were significantly associated with exposure to HBV. After adding poverty index, health insurance, IDU, and HCV status, there was a significant association between being female (aOR 2.54, 95\% CI $1.27-5.07$ ), 60 to 69 years old (5.67, 95\% CI $1.04-30.96$ ), living below the poverty threshold (aOR 3.14, 95\% CI 1.47 - 6.74), IDU (aOR 4.82, 95\% CI $2.05-11.31$ ), and active $\mathrm{HCV}$ infection (aOR 2.85, 95\% CI 1.05 - 7.78). In model 3, after adjusting for all exposure variables there was a significant association between being female (aOR 3.83, 95\% CI $1.65-8.90$ ) and exposure to $\mathrm{HBV}$, as well as living below the poverty threshold (aOR 3.17, 95\% CI 1.39 - 7.21), IDU (aOR 4.89, 95\% CI 1.95 - 12.26), active HCV infection (aOR 3.39, 95\% CI 1.10 - 12.26), and identifying as MSM (aOR 28.21, 95\% CI $5.19-153.38$ ).

To answer methamphetamine specific questions, participants had to answer 'yes' to ever using cocaine, heroin, or methamphetamine. Missing data for this inclusion question were examined. Among all participants, 19,998 were eligible to answer the question and data were missing for 2,587 (12.9\%) participants. The odds of missing values were higher for females, younger participants, non-Hispanic blacks, and other races. All odds ratios indicated weak associations between missing values and the demographic variables. Based on these findings selection bias did not appear to be a factor.

\section{DISCUSSION}

In this study, eight years of NHANES data were evaluated in order to provide estimates of the U.S. non-institutionalized population representing over 11 million people who reported ever using methamphetamine. The use of lab markers provided accurate estimates of hepatitis B exposure and hepatitis $\mathrm{C}$ infection in this population. Compared to the overall study population who reported ever using methamphetamine, a disproportionate amount of the HBV exposed group comprised of females, persons with active HCV infection, MSM, participants 50 to 69 years old (baby boomers), participants living below the poverty threshold, and those reporting 
IDU. In bivariate analysis, the odds of HBV exposure among those who reported using methamphetamine $\geq 50$ times was five times higher compared to those who used $\leq 5$ times, suggesting an increased odds of exposure with increased use. In the full model, four of the significant associations were consistent with previously identified risk factors for acquiring hepatitis B infection, including living below the poverty threshold, IDU, active HCV infection, and self-identifying as MSM [4, 20]. Also, being female was significantly associated with HBV exposure. After adjusting for all co-variates, the odds of hepatitis B exposure for females who reported using methamphetamine was nearly four times higher compared to males. Interestingly, in this study, reporting multiple sexual partners was not associated with hepatitis B exposure. This result was unexpected considering high-risk sexual practices, including multiple sexual partners, is associated with both methamphetamine use and hepatitis B infection. However, while methamphetamine use was reported as ever having used in lifetime, the number of sexual partners was only reported for the previous year.

Nationwide, an increase in HCV infection among reproductive age women and a rise in babies born with neonatal abstinence syndrome indicates increased drug use among women in general [21, 22]. In light of the 2019 MMWR study highlighting the increase in methamphetamine use among females with primary and secondary syphilis, the results from this study suggest a similar pattern for HBV exposure in females using methamphetamine [23]. Additionally, a study analyzing hospital delivery data from 2004 to 2015 found an increasing trend of amphetamine use among women delivering a baby; amphetamine use was reported in 2.4 per 1,000 hospital deliveries in 2014 to 2015 [24].

Some of the exposures identified in this study were consistent with previous studies; however, the significant association between females who reported methamphetamine use and HBV exposure suggests increased efforts may be needed for this population subgroup. These findings highlight the importance of screening for substance use including methamphetamine, as well as testing and vaccinating for $\mathrm{HBV}$ among reproductive-age women to prevent mother-to-child transmission of HBV during pregnancy. The U.S. Preventive Services Task Force recently reaffirmed their recommendation that all pregnant women be screened for HBV at the first prenatal visit highlighting the important role of obstetrician-gynecologists in providing primary care including HBV screening and vaccination [25]. Additionally, harm reduction programs 
provide another avenue to reach high-risk individuals, including women, who may not access primary care services.

NHANES is a cross-sectional study design and temporality between risk factors and HBV exposure cannot be established. It is not possible to know if HBV exposure occurred as a result of methamphetamine use or if use is a potential marker for other high-risk behaviors. Additionally, a relatively small sample size and subcategories used in analyses resulted in a number of wide confidence intervals and these results should be interpreted with caution. Participants were included in the study if they reported 'ever using' methamphetamine. The sensitive nature of questions regarding drug use and sexual behavior may result in people not answering certain questions or not answering accurately resulting in incorrect estimates arising from potential non-response or misclassification bias. However, these questions were selfadministered using an Audio Computer-Assisted Self Interview system in a private room during the medical exam component of the survey, which may have resulted in participants feeling more comfortable to respond truthfully. Finally, susceptibility to HBV was determined as the absence of all HBV lab markers, including anti-HBs. In vaccinated persons, anti-HBs wanes over time, therefore some participants included in the susceptible comparison group may have vaccineinduced immunity with anti-HBs levels below detectable levels. NHANES data do not include incarcerated or homeless individuals; this may affect the generalizability of results to the entire U.S. population.

\section{CONCLUSION}

As methamphetamine use continues to rise, it is important to identify those at highest risk of acquiring hepatitis B infections in order to target testing and vaccination programs. The estimated number of susceptible participants who reported using methamphetamine in this study suggests a need to provide targeted vaccination efforts in this potentially at-risk population. Harm reduction programs should incorporate testing for $\mathrm{HBV}$ and vaccination to help reduce the disease burden among this high-risk group. Additionally, the results from this study indicates a need to target not only high-risk individuals but also older individuals who may not have benefited from the HBV birth dose or adolescent catch-up vaccination. Finally, the association of HBV exposure with active HCV infection suggests shared risk factors and efforts for HBV prevention can potentially be incorporated with existing efforts to reduce HCV transmission. 


\section{LITERATURE CITED}

1. Kowdley KV, Wang CC, Welch S, Roberts H, Brosgart CL. Prevalence of chronic hepatitis B among foreign-born persons living in the United States by country of origin. Hepatology 2012; $56: 422-33$.

2. Roberts H, Kruszon-Moran D, Ly KN, et al. Prevalence of chronic hepatitis B virus (HBV) infection in U.S. households: National Health and Nutrition Examination Survey (NHANES), 1988-2012. Hepatology 2016; 63:388-97.

3. Trépo C, Chan HL, Lok A. Hepatitis B virus infection. Lancet 2014; 384:2053-63.

4. Weinbaum C, Williams I, Mast E, et al. Centers for Disease Control and Prevention (CDC) Recommendations for identification and public health management of persons with chronic hepatitis B virus infection. MMWR Recomm Rep 2008; 57:1-20.

5. Hepatitis B. In: Hamborsky J, Kroger A, Wolfe S, eds. Centers for Disease Control and Prevention. Epidemiology and prevention of vaccine-preventable diseases. 13th ed. Washington DC: Public Health Foundation, 2015; 149-174.

6. Van Buren RC, Schaffner W. Hepatitis B virus: a comprehensive strategy for eliminating transmission in the United States through universal childhood vaccination. Recommendations of the Immunization Practices Advisory Committee (ACIP). MMWR Recomm Rep 1991; 40:1-19.

7. Centers for Disease Control and Prevention. Update: recommendations to prevent hepatitis B virus transmission--United States. MMWR Recomm Rep 1999; 48:33.

8. Harris AM, Iqbal K, Schillie S, et al. Increases in acute hepatitis B virus infections Kentucky, Tennessee, and West Virginia, 2006-2013. MMWR Morb Mortal Wkly Rep 2016; 65:47-50.

9. Espinosa CM, Jhaveri R. Update on the management of hepatitis B and C infections in the neonatal period. Semin Perinatol 2018; 42:185-190.

10. Schillie S, Vellozzi C, Reingold A, et al. Prevention of hepatitis B virus infection in the United States: Recommendations of the Advisory Committee on Immunization Practices. MMWR Recomm Rep 2018; 67:1-31.

11. Centers for Disease Control and Prevention. Hepatitis B questions and answers for health professionals. Available at: https://www.cdc.gov/hepatitis/hbv/hbvfaq.htm. Accessed 13 April 2019.

12. Opioids and methamphetamine: a tale of two crises. Editorial. Lancet 2018; 391:713.

13. Hedegaard H, Bastian BA, Trinidad JP, Spencer M, Warner M. Drugs most frequently involved in drug overdose deaths: United States, 2011-2016. Natl Vital Stat Rep 2018; 67:1-14. 
14. Ellis MS, Kasper ZA, Cicero TJ. Twin epidemics: The surging rise of methamphetamine use in chronic opioid users. Drug Alcohol Depend 2018; 193:14-20.

15. National Institute on Drug Abuse. Methamphetamine. Available at: https://www.drugabuse.gov/publications/drugfacts/methamphetamine. Accessed 13 April 2019.

16. Vogt TM, Perz JF, Van Houten CK, et al. An outbreak of hepatitis B virus infection among methamphetamine injectors: the role of sharing injection drug equipment. Addiction 2006; 101:726-30.

17. Hutin YJ, Sabin KM, Hutwagner LC, et al. Multiple modes of hepatitis A virus transmission among methamphetamine users. Am J Epidemiol 2000; 152:186-92.

18. Pursaga J. Meth use causing hepatitis B outbreak in Winnipeg. Winnipeg Sun, 2018. Available at: https://winnipegsun.com/news/news-news/meth-use-causing-hepatitis-b-outbreakin-winnipeg. Accessed 14 April 2019.

19. Centers for Disease Control and Prevention (CDC). National Center for Health Statistics (NCHS). National Health and Nutrition Examination Survey data. Hyattsville, MD: U.S. Department of Health and Human Services, Centers for Disease Control and Prevention. Available at: www.cdc.gov/nchs/nhanes/index.htm.

20. Ioannou GN. Hepatitis B virus in the United States: infection, exposure, and immunity rates in a nationally representative survey. Ann Intern Med 2011; 154:319-28.

20. Hittner JB. Meta-analysis of the association between methamphetamine use and high-risk sexual behavior among heterosexuals. Psychology Addict Behav 2016; 30:147-57.

21. Ly KN, Jiles RB, Teshale EH, Foster MA, Pesano RL, Holmberg SD. Hepatitis C virus infection among reproductive-aged women and children in the United States, 2006 to 2014. Ann Intern Med 2017; 166:775-82.

22. Sanlorenzo LA, Stark AR, Patrick SW. Neonatal abstinence syndrome: an update. Curr Opin Pediatr 2018; 30:182.

23. Kidd SE, Grey JA, Torrone EA, Weinstock HS. Increased methamphetamine, injection drug, and heroin use among women and heterosexual men with primary and secondary syphilis United States, 2013-2017. MMWR Morb Mortal WKLY Rep 2019; 68:144-8.

24. Admon LK, Bart G, Kozhimannil KB, Richardson CR, Dalton VK, Winkelman TNA. Amphetamine- and opioid-affected births: Incidence, outcomes, and costs, United States, 20042015. Am J Public Health 2018:e1-e7.

25. US Preventitive Services Task Force. Screening for hepatitis B virus infection in pregnant women: US Preventive Services Task Force reaffirmation recommendation statement. JAMA 2019; 322:349-54. 
Figure 3.1 Flow chart of sample size selection - NHANES, 2009-2016

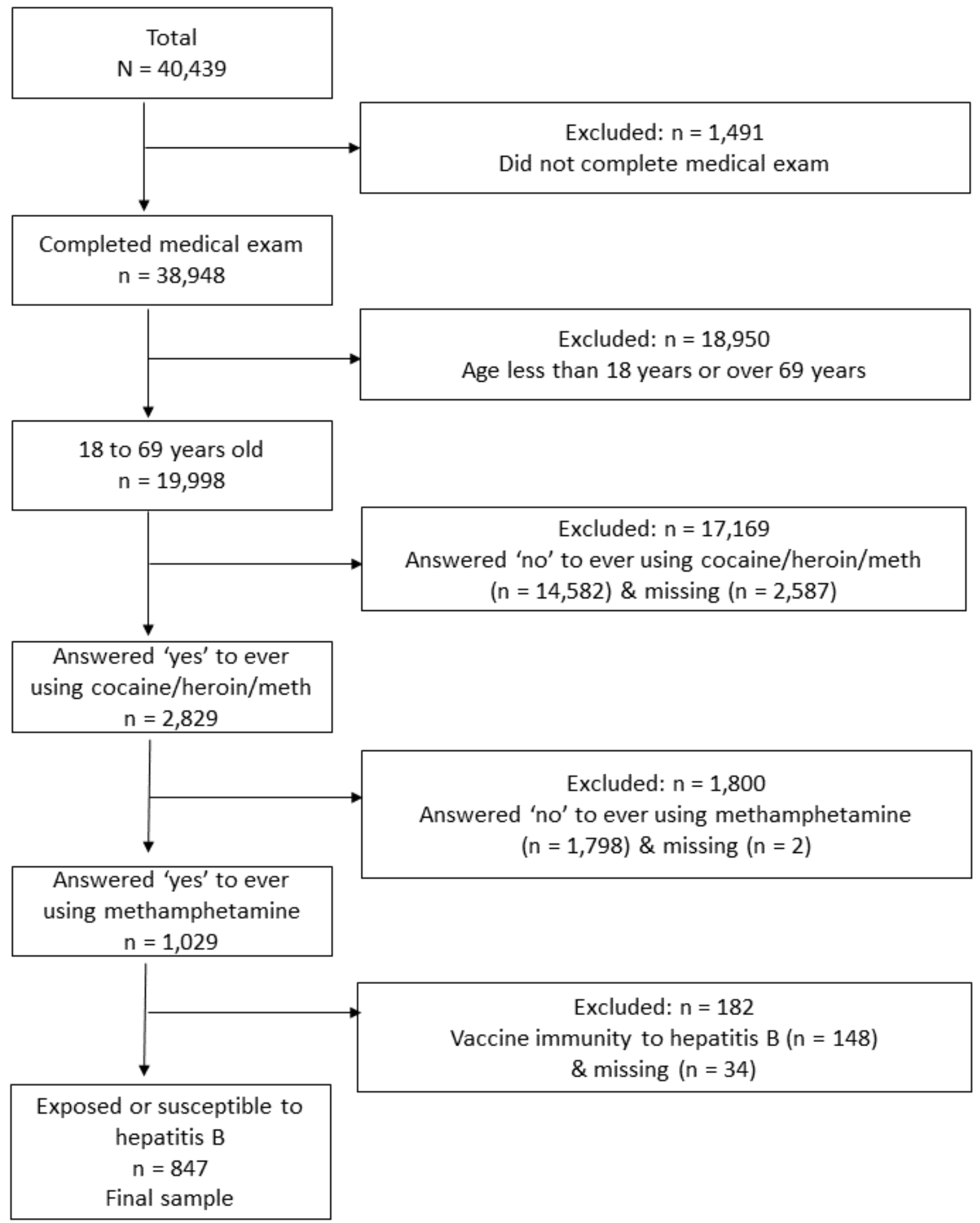


Table 3.1 Descriptive statitics, weighted percents, weighted frequencies, and standard errors for exposure variables and HBV status

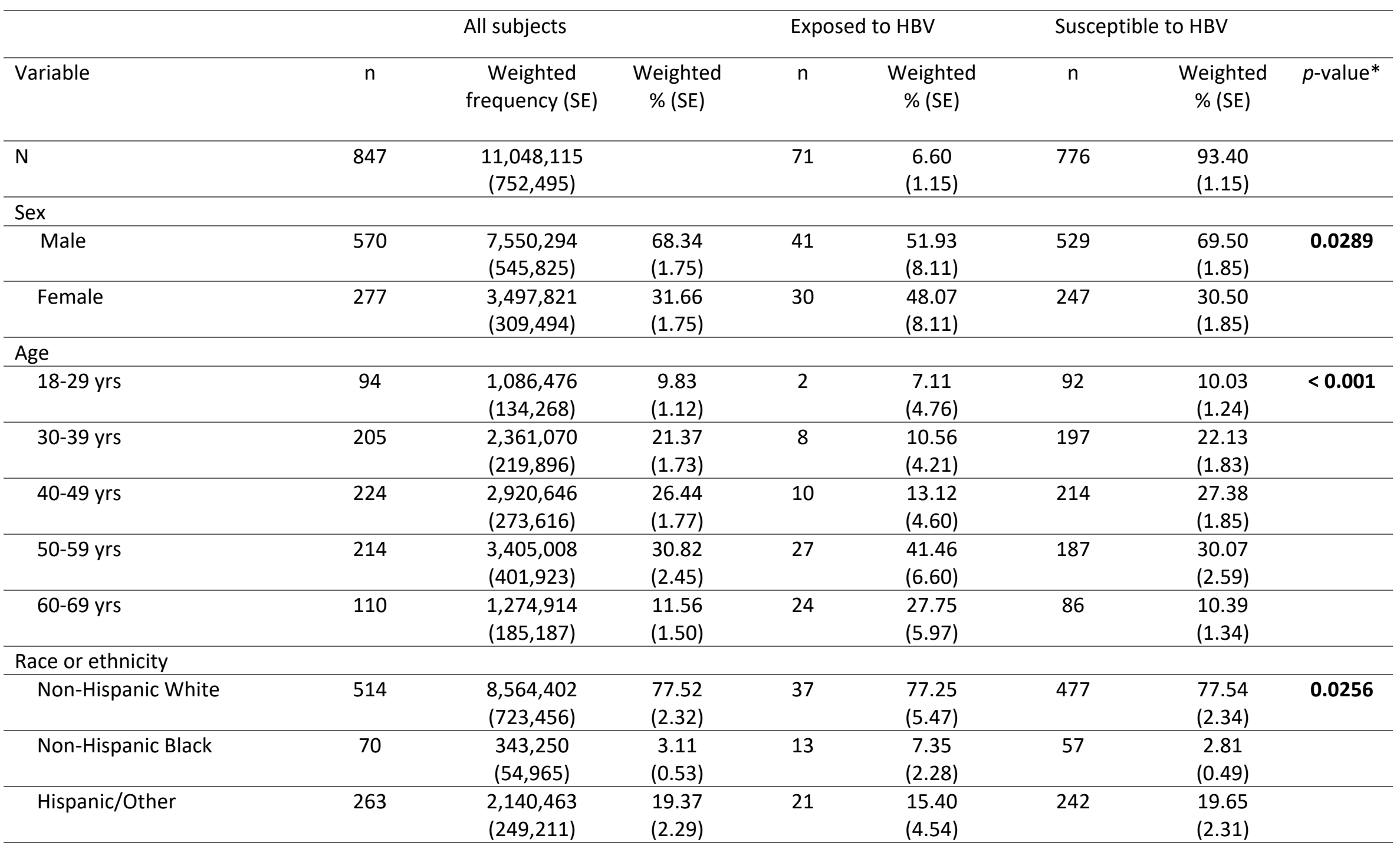




\begin{tabular}{|c|c|c|c|c|c|c|c|c|}
\hline \multicolumn{9}{|l|}{ Poverty Index } \\
\hline Below threshold & 205 & $\begin{array}{l}1,656,518 \\
(186,424)\end{array}$ & $\begin{array}{l}14.99 \\
(1.56)\end{array}$ & 30 & $\begin{array}{l}35.39 \\
(6.49)\end{array}$ & 175 & $\begin{array}{l}13.55 \\
(1.47)\end{array}$ & $<0.001$ \\
\hline 1 to 1.9 & 245 & $\begin{array}{l}2,530,213 \\
(300,853)\end{array}$ & $\begin{array}{l}22.90 \\
(2.00)\end{array}$ & 14 & $\begin{array}{l}16.44 \\
(5.94)\end{array}$ & 231 & $\begin{array}{l}23.36 \\
(2.05)\end{array}$ & \\
\hline$\geq 2.0$ & 356 & $\begin{array}{l}6,474,304 \\
(560,244)\end{array}$ & $\begin{array}{l}58.60 \\
(2.84)\end{array}$ & 22 & $\begin{array}{l}41.82 \\
(7.59)\end{array}$ & 334 & $\begin{array}{l}59.79 \\
(2.92)\end{array}$ & \\
\hline Missing & 41 & $\begin{array}{l}387,079 \\
(82,035)\end{array}$ & $\begin{array}{c}3.50 \\
(0.78)\end{array}$ & 5 & $\begin{array}{c}6.34 \\
(4.17) \\
\end{array}$ & 36 & $\begin{array}{c}3.30 \\
(0.77)\end{array}$ & \\
\hline \multicolumn{9}{|l|}{ Health Insurance } \\
\hline Yes & 572 & $\begin{array}{l}8,072,221 \\
(594,938)\end{array}$ & $\begin{array}{l}73.06 \\
(1.77)\end{array}$ & 50 & $\begin{array}{l}70.66 \\
(7.52)\end{array}$ & 522 & $\begin{array}{l}73.23 \\
(1.87)\end{array}$ & 0.7392 \\
\hline No & 275 & $\begin{array}{l}2,975,894 \\
(272,768)\end{array}$ & $\begin{array}{l}26.94 \\
(1.77)\end{array}$ & 21 & $\begin{array}{l}29.34 \\
(7.52)\end{array}$ & 254 & $\begin{array}{l}26.77 \\
(1.87)\end{array}$ & \\
\hline Injection Drug Use & & & & & & & & $<.0001$ \\
\hline No & 669 & $\begin{array}{c}8,804,721 \\
(607,8181)\end{array}$ & $\begin{array}{l}79.69 \\
(1.71) \\
\end{array}$ & 26 & $\begin{array}{l}42.10 \\
(8.83) \\
\end{array}$ & 643 & $\begin{array}{l}82.35 \\
(1.82) \\
\end{array}$ & \\
\hline Yes & 177 & $\begin{array}{l}2,234,510 \\
(254,403)\end{array}$ & $\begin{array}{l}20.23 \\
(1.70)\end{array}$ & 44 & $\begin{array}{l}56.68 \\
(8.58)\end{array}$ & 133 & $\begin{array}{l}17.65 \\
(1.82)\end{array}$ & \\
\hline Missing & 1 & $8,884(8,884)$ & $\begin{array}{c}0.08 \\
(0.08)\end{array}$ & 1 & $\begin{array}{c}1.22 \\
(1.19)\end{array}$ & 0 & $\mathrm{~N} / \mathrm{A}$ & \\
\hline $\mathrm{HCV}$ & & & & & & & & $<.0001$ \\
\hline Negative & 774 & $\begin{array}{c}10,169,052 \\
(673,644)\end{array}$ & $\begin{array}{l}92.04 \\
(1.17)\end{array}$ & 41 & $\begin{array}{l}69.48 \\
(6.86) \\
\end{array}$ & 733 & $\begin{array}{l}93.64 \\
(1.11)\end{array}$ & \\
\hline $\begin{array}{l}\text { Positive } \\
\text { (Active Infection) }\end{array}$ & 65 & $\begin{array}{c}767,823 \\
(139,351) \\
\end{array}$ & $\begin{array}{c}6.95 \\
(1.13) \\
\end{array}$ & 26 & $\begin{array}{l}28.47 \\
(6.90)\end{array}$ & 39 & $\begin{array}{c}5.43 \\
(1.03) \\
\end{array}$ & \\
\hline Missing & 8 & $\begin{array}{l}111,240 \\
(62,835) \\
\end{array}$ & $\begin{array}{c}1.01 \\
(0.54)\end{array}$ & 4 & $\begin{array}{c}2.05 \\
(1.11)\end{array}$ & 4 & $\begin{array}{c}0.93 \\
(0.58) \\
\end{array}$ & \\
\hline $\begin{array}{l}\text { Education } \\
(20+y r s)\end{array}$ & & & & & & & & \\
\hline$<12$ H.S. & 176 & $\begin{array}{l}1,676,636 \\
(174,344)\end{array}$ & $\begin{array}{l}15.18 \\
(1.54) \\
\end{array}$ & 11 & $\begin{array}{l}14.19 \\
(5.08)\end{array}$ & 165 & $\begin{array}{l}15.25 \\
(1.61)\end{array}$ & 0.8320 \\
\hline$\geq 12$ H.S. or GED & 663 & $\begin{array}{l}9,308,227 \\
(704,975)\end{array}$ & $\begin{array}{l}84.25 \\
(1.58)\end{array}$ & 60 & $\begin{array}{l}85.81 \\
(5.08)\end{array}$ & 603 & $\begin{array}{l}84.14 \\
(1.65)\end{array}$ & \\
\hline
\end{tabular}




\begin{tabular}{|c|c|c|c|c|c|c|c|c|}
\hline Missing & 8 & $63,252(29,626)$ & $\begin{array}{c}0.57 \\
(0.27)\end{array}$ & 0 & $N / A$ & 8 & $\begin{array}{c}0.61 \\
(0.28)\end{array}$ & \\
\hline \multicolumn{9}{|l|}{$\begin{array}{l}\text { Number or times used } \\
\text { (18-59 yrs) }\end{array}$} \\
\hline$\leq 5$ times & 227 & $\begin{array}{l}3,297,439 \\
(300,396)\end{array}$ & $\begin{array}{l}29.85 \\
(2.71)\end{array}$ & 8 & $\begin{array}{c}9.63 \\
(3.98)\end{array}$ & 219 & $\begin{array}{l}31.28 \\
(2.74)\end{array}$ & $<0.001$ \\
\hline 6-49 times & 241 & $\begin{array}{l}3,305,169 \\
(367,890)\end{array}$ & $\begin{array}{l}29.92 \\
(2.06)\end{array}$ & 14 & $\begin{array}{l}20.08 \\
(5.59)\end{array}$ & 227 & $\begin{array}{l}30.61 \\
(2.17)\end{array}$ & \\
\hline$\geq 50$ times & 267 & $\begin{array}{l}3,155,935 \\
(339,479)\end{array}$ & $\begin{array}{l}28.57 \\
(2.04)\end{array}$ & 25 & $\begin{array}{l}42.54 \\
(8.51)\end{array}$ & 242 & $\begin{array}{l}27.58 \\
(2.03)\end{array}$ & \\
\hline $\begin{array}{l}\text { Missing } \\
\text { (ages } 60 \text { to } 69, n=110 \text { ) }\end{array}$ & 112 & $\begin{array}{l}1,289,571 \\
(185,532)\end{array}$ & $\begin{array}{l}11.67 \\
(1.50)\end{array}$ & 24 & $\begin{array}{l}27.75 \\
(5.97)\end{array}$ & 88 & $\begin{array}{l}10.54 \\
(1.34)\end{array}$ & \\
\hline \multicolumn{9}{|l|}{$\begin{array}{l}\text { Sexual Identity } \\
\text { (18-59 yrs) }\end{array}$} \\
\hline Heterosexual & 663 & $\begin{array}{l}8,914,926 \\
(662,502)\end{array}$ & $\begin{array}{l}80.69 \\
(1.51)\end{array}$ & 35 & $\begin{array}{l}57.00 \\
(7.13)\end{array}$ & 628 & $\begin{array}{l}82.37 \\
(1.51)\end{array}$ & $<0.001$ \\
\hline MSM & 25 & $\begin{array}{l}323,237 \\
(84,470)\end{array}$ & $\begin{array}{c}2.93 \\
(0.79)\end{array}$ & 7 & $\begin{array}{l}10.47 \\
(4.79)\end{array}$ & 18 & $\begin{array}{c}2.39 \\
(0.76)\end{array}$ & \\
\hline Other & 46 & $\begin{array}{c}514,367 \\
(105,628)\end{array}$ & $\begin{array}{c}4.66 \\
(0.91)\end{array}$ & 4 & $\begin{array}{c}4.03 \\
(2.29)\end{array}$ & 42 & $\begin{array}{c}4.70 \\
(0.98)\end{array}$ & \\
\hline $\begin{array}{l}\text { Missing } \\
\text { (ages } 60 \text { to } 69, \mathrm{n}=110 \text { ) }\end{array}$ & 113 & $\begin{array}{l}1,295,585 \\
(184,607)\end{array}$ & $\begin{array}{l}11.73 \\
(1.50)\end{array}$ & 25 & $\begin{array}{l}28.50 \\
(6.00)\end{array}$ & 88 & $\begin{array}{l}10.54 \\
(1.36)\end{array}$ & \\
\hline $\begin{array}{l}\text { Sex Partners in Past Year } \\
\text { (18-59 yrs) }\end{array}$ & & & & & & & & $<0.001$ \\
\hline$<2$ & 531 & $\begin{array}{l}7,265,830 \\
(583,348)\end{array}$ & $\begin{array}{l}65.77 \\
(2.13)\end{array}$ & 33 & $\begin{array}{l}50.53 \\
(8.46)\end{array}$ & 498 & $\begin{array}{l}66.84 \\
(2.15)\end{array}$ & \\
\hline$\geq 2$ & 206 & $\begin{array}{l}2,507,370 \\
(255,002)\end{array}$ & $\begin{array}{l}22.70 \\
(1.98)\end{array}$ & 14 & $\begin{array}{l}21.71 \\
(6.28)\end{array}$ & 192 & $\begin{array}{l}22.76 \\
(2.02)\end{array}$ & \\
\hline $\begin{array}{c}\text { Missing } \\
\text { (ages } 60 \text { to } 69, n=110 \text { ) }\end{array}$ & 110 & $\begin{array}{l}1,274,914 \\
(185,187)\end{array}$ & $\begin{array}{l}11.54 \\
(1.50)\end{array}$ & 24 & $\begin{array}{l}27.75 \\
(5.97)\end{array}$ & 86 & $\begin{array}{l}10.39 \\
(1.34)\end{array}$ & \\
\hline
\end{tabular}

${ }^{*} p$-value for Rao-Scott Chi-squared test statistic

$\mathrm{HCV}=$ Hepatitis $\mathrm{C}$ virus, $\mathrm{HS}=$ High School, GED = General Education Development, MSM = Men who have sex with men 
Table 3.2 Unadjusted and adjusted odds ratios for association between exposure variables and HBV status

\begin{tabular}{|c|c|c|c|c|}
\hline & & Model 1* & Model $2 \dagger$ & $\begin{array}{c}\text { Model } 3 \neq \\
\text { (ages } 20 \text { to } 59\end{array}$ \\
\hline Variable & $\begin{array}{c}\text { uOR } \\
(95 \% \mathrm{Cl})\end{array}$ & $\begin{array}{c}\mathrm{aOR} \\
(95 \% \mathrm{Cl})\end{array}$ & $\begin{array}{c}\text { aOR } \\
(95 \% \mathrm{Cl})\end{array}$ & $\begin{array}{c}\mathrm{aOR} \\
(95 \% \mathrm{Cl})\end{array}$ \\
\hline \multicolumn{5}{|l|}{ Sex } \\
\hline Male & 1 & 1 & 1 & 1 \\
\hline Female & $\begin{array}{c}\mathbf{2 . 1 1} \\
(1.05-4.26)\end{array}$ & $\begin{array}{c}\mathbf{2 . 1 8} \\
(1.06-4.51)\end{array}$ & $\begin{array}{c}\mathbf{2 . 5 4} \\
(1.27-5.07)\end{array}$ & $\begin{array}{c}\mathbf{3 . 8 3} \\
(1.65-8.90)\end{array}$ \\
\hline \multicolumn{5}{|l|}{ Age } \\
\hline $18-29$ yrs & 1 & 1 & 1 & 1 \\
\hline $30-39$ yrs & $\begin{array}{c}0.67 \\
(0.12-3.72)\end{array}$ & $\begin{array}{c}0.72 \\
(0.13-3.90)\end{array}$ & $\begin{array}{c}0.89 \\
(0.17-4.77)\end{array}$ & $\begin{array}{c}0.83 \\
(0.10-6.80)\end{array}$ \\
\hline $40-49$ yrs & $\begin{array}{c}0.676 \\
(0.13-3.66)\end{array}$ & $\begin{array}{c}0.73 \\
(0.13-3.96)\end{array}$ & $\begin{array}{c}0.55 \\
(0.1003 .03)\end{array}$ & $\begin{array}{c}0.50 \\
(0.07-3.67)\end{array}$ \\
\hline $50-59$ yrs & $\begin{array}{c}1.95 \\
(0.39-9.60)\end{array}$ & $\begin{array}{c}2.02 \\
(0.39-10.60)\end{array}$ & $\begin{array}{c}1.78 \\
(0.38-8.42)\end{array}$ & $\begin{array}{c}1.79 \\
(0.23-13.95)\end{array}$ \\
\hline $60-69$ yrs & $\begin{array}{c}3.77 \\
(0.76-18.72)\end{array}$ & $\begin{array}{c}4.02 \\
(0.80-20.30)\end{array}$ & $\begin{array}{c}5.67 \\
(1.04-30.96)\end{array}$ & NA \\
\hline \multicolumn{5}{|l|}{ Race or ethnicity } \\
\hline Non-Hispanic White & 1 & 1 & 1 & 1 \\
\hline Non-Hispanic Black & $\begin{array}{c}\mathbf{2 . 6 3} \\
(1.30-5.30)\end{array}$ & $\begin{array}{c}\mathbf{2 . 3 7} \\
(1.09-5.14)\end{array}$ & $\begin{array}{c}1.53 \\
(0.52-4.53)\end{array}$ & $\begin{array}{c}1.99 \\
(0.52-7.67)\end{array}$ \\
\hline Hispanic/Other & $\begin{array}{c}0.786 \\
(0.41-1.52)\end{array}$ & $\begin{array}{c}1.17 \\
(0.59-2.31)\end{array}$ & $\begin{array}{c}1.01 \\
(0.49-2.10)\end{array}$ & $\begin{array}{c}0.97 \\
(0.44-2.14)\end{array}$ \\
\hline \multicolumn{5}{|l|}{ Poverty Index } \\
\hline Below threshold & $\begin{array}{c}3.73 \\
(1.93-7.21)\end{array}$ & & $\begin{array}{c}3.14 \\
(1.47-6.74)\end{array}$ & $\begin{array}{c}\mathbf{3 . 1 7} \\
(1.39-7.21)\end{array}$ \\
\hline 1 to 1.9 & $\begin{array}{c}1.06 \\
(0.39-2.63)\end{array}$ & & $\begin{array}{c}0.98 \\
(0.34-2.87)\end{array}$ & $\begin{array}{c}0.99 \\
(0.32-3.06)\end{array}$ \\
\hline$\geq 2.0$ & 1 & & 1 & 1 \\
\hline \multicolumn{5}{|l|}{ Health Insurance } \\
\hline Yes & 1 & & 1 & 1 \\
\hline No & $\begin{array}{c}1.14 \\
(0.53-2.45)\end{array}$ & & $\begin{array}{c}1.22 \\
(0.46-3.22)\end{array}$ & $\begin{array}{c}1.58 \\
(0.61-4.01)\end{array}$ \\
\hline \multicolumn{5}{|l|}{ Injection Drug Use } \\
\hline No & 1 & & 1 & 1 \\
\hline Yes & $\begin{array}{c}6.28 \\
(2.77-14.26)\end{array}$ & & $\begin{array}{c}4.82 \\
(2.05-11.31)\end{array}$ & $\begin{array}{c}4.89 \\
(1.95-12.26)\end{array}$ \\
\hline \multicolumn{5}{|l|}{$\mathrm{HCV}$} \\
\hline Negative & 1 & & 1 & 1 \\
\hline Positive & $\begin{array}{c}7.07 \\
(3.24-15.44)\end{array}$ & & $\begin{array}{c}\mathbf{2 . 8 5} \\
(1.05-7.78)\end{array}$ & $\begin{array}{c}\mathbf{3 . 3 9} \\
(1.10-12.26)\end{array}$ \\
\hline \multicolumn{5}{|l|}{ Education $(20+y r s)$} \\
\hline$<12$ H.S. & 1 & & & 1 \\
\hline
\end{tabular}




\begin{tabular}{|c|c|c|}
\hline$\geq 12$ H.S. or GED & $\begin{array}{c}1.10 \\
(0.46-2.60)\end{array}$ & $\begin{array}{c}1.39 \\
(0.31-6.34)\end{array}$ \\
\hline \multicolumn{3}{|c|}{$\begin{array}{l}\text { Number or times used } \\
(18-59 \text { yrs) }\end{array}$} \\
\hline$\leq 5$ times & 1 & 1 \\
\hline 6-49 times & $\begin{array}{c}2.13 \\
(0.78-5.79)\end{array}$ & $\begin{array}{c}1.65 \\
(0.54-5.06)\end{array}$ \\
\hline$\geq 50$ times & $\begin{array}{c}\mathbf{5 . 0 1 1} \\
(1.88-13.35)\end{array}$ & $\begin{array}{c}2.78 \\
(0.67-11.47)\end{array}$ \\
\hline \multicolumn{3}{|l|}{$\begin{array}{l}\text { Sexual Identity } \\
\text { (18-59 yrs) }\end{array}$} \\
\hline Heterosexual & 1 & 1 \\
\hline MSM & $\begin{array}{c}6.33 \\
(1.81-22.14)\end{array}$ & $\begin{array}{c}\mathbf{2 8 . 2 1} \\
(5.19-153.38)\end{array}$ \\
\hline Other & $\begin{array}{c}1.24 \\
(0.33-4.71)\end{array}$ & $\begin{array}{c}0.55 \\
(0.07-4.41)\end{array}$ \\
\hline \multicolumn{3}{|c|}{$\begin{array}{l}\text { Sex Partners in Past Year } \\
(18-59 \text { yrs })\end{array}$} \\
\hline$<2$ & 1 & 1 \\
\hline$\geq 2$ & $\begin{array}{c}1.262 \\
(0.53-3.0)\end{array}$ & $\begin{array}{c}1.19 \\
(0.35-4.06)\end{array}$ \\
\hline \multicolumn{3}{|c|}{$\begin{array}{l}\mathrm{HCV}=\text { Hepatitis C virus, HS = High School, GED = General Education Development, MSM = Men who } \\
\text { have sex with men }\end{array}$} \\
\hline \multicolumn{3}{|c|}{ *Model 1 includes sex, age, and race/ethnicity } \\
\hline 'Model 2 includes sex & nicity, poverty $\mathrm{i}$ & $\mathrm{HCV}$ \\
\hline
\end{tabular}




\section{CONCLUSION}

Despite decreasing trends nationwide, WV's rate of acute hepatitis B increased from 2002 to 2016, and was 12 times higher than the US rate in 2017 [1]. A safe and effective HBV vaccine has existed for almost four decades, yet HBV continues to be problematic in certain at-risk groups. Ongoing transmission indicates the need for continual efforts to identify changing hepatitis B trends and the necessity to evaluate the effectiveness of vaccine interventions meant to reach those most at risk. The specific aims of our three studies were to assess changes in the acute hepatitis B in WV over the past decade, evaluate the effectiveness of vaccinating at-risk individuals in settings outside LHD STD clinics, and understand factors associated with HBV exposure in an emerging at-risk group of people who report using methamphetamine. Notable findings of our research include:

- A shift in the WV county-level hotspot of acute hepatitis B rate over the past decade and a significant rate decrease in half of the WV Pilot Project counties after vaccine distribution.

- Increased odds of completing all three doses of hepatitis B vaccine at substance use treatment centers and LHD family planning clinics as well as receipt of at least two doses at substance use treatment centers, LHD family planning clinics, and correctional facilities compared to WV Pilot Project participants vaccinated through LHD STD clinics.

- Higher odds of HBV exposure among women who reported using methamphetamine, as well as those living below the poverty threshold, people with active HCV infection, men identifying as MSM, or self-identifying as a person who injects drugs [2].

Results from our geospatial analyses can help identify areas in current need of enhanced hepatitis B surveillance and guide placement of harm reduction services including HBV testing and vaccination. However, ongoing geospatial analyses are needed to visualize and monitor trends over time and test for statistically significant hotspots of HBV transmission. Additionally, unique approaches, including Bland-Altman analysis and graphing, provide a way to evaluate HBV prevention efforts at the county-level by visualizing significant rate differences in relation to the WV mean difference after project implementation. 
In addition to monitoring trends in county-level data, evaluation of participant-level data is key to understanding successful aspects of vaccination programs in at-risk group. For our WV Pilot Project participant study, data were available for over half of the LHDs representing 1,201 participants. While most participants were vaccinated through LHD STD clinics, there were increased odds of receiving all three doses if vaccinated through substance use treatment centers or LHD family planning clinics. Given that IDU and street drug use are the two most commonly reported risk factors among persons with acute $\mathrm{HBV}$ infection in $\mathrm{WV}$, our findings indicate vaccination services provided through partnerships between LHDs and substance use treatment centers may result in more at-risk adults both receiving and completing the HBV series [3, 4]. Study results also indicate there were increased odds of receiving at least two doses at substance use treatment centers, LHD family planning clinics, and correctional facilities. In 2016, incarceration was the third most common risk factor among people with acute HBV infection [4]. Regional jails and drug courts are another way LHDs can successfully vaccinate at-risk individuals with either two doses of the traditional three-dose HBV series or both doses of the new highly immunogenic Heplisav-B vaccine.

Finally, our findings indicate that people reporting methamphetamine use in a nationally representative survey of the noninstitutionalized population, have similar factors associated with HBV exposure as those previously identified including identifying as MSM, active HCV infection, living below the poverty threshold, and IDU [5-7]. Based on these results, vaccination efforts can potentially reach those at-risk by targeting groups already known to have an increased risk of exposure. However, a notable finding of our study was the odds of HBV exposure was four times higher in women who reported using methamphetamine compared to men. These findings coupled with increases in HCV infections and HBV exposure among women of childbearing age highlight the need to provide testing and vaccination to women [8-11]. Results from the WV Pilot Project indicate that LHD family planning clinics can serve as an important way to reach women and ensure they complete the HBV vaccine series thus protecting them and future generations.

Despite the availability of a safe and effective hepatitis B vaccine, many individuals remain at risk of infection. Hepatitis B virus transmission continues in WV due in part to injection drug use 
and substance misuse. Ongoing efforts are needed to identify trends, guide testing and vaccination programs, and evaluate the effectiveness of those programs. 


\section{LITERATURE CITED}

1. Centers for Disease Control and Prevention. Viral Hepatitis Statistics \& Surveillance. Available at: https://www.cdc.gov/hepatitis/statistics/index.htm. Accessed 8 March 2020.

2. Tressler SR, Kushner T, Bhandari R. Factors associated with hepatitis B exposure among people who report using methamphetamine: NHANES 2009-2016. J Infect Dis. 2020: 221(2): 243-250.

3. Anil L, Simmons A. West Virginia viral hepatitis B and C surveillance 2012-2015. West Virginia Department of Health and Human Resources Bureau for Public Health. 2016. Available at: http://dhhr.wv.gov/oeps/disease/viral-hepatitis/documents/Hepatitis-Report-2016.pdf.

Accessed 8 March 2020.

4. Office of Epidemiology and Prevention Services. Hepatitis B and Hepatitis C Infection in West Virginia - 2016 Surveillance Summary. Available at:

https://oeps.wV.gov/hepatitis/documents/data/Summary_2016_Acute_HBV-HCV.pdf. Accessed 3 March 2020.

5. Shing JZ, Ly KN, Xing J, Teshale EH, Jiles RB. Prevalence of hepatitis B virus infection among US adults aged 20-59 years with a history of injection drug use: National Health and Nutrition Examination Survey, 2001-2016. Clin Infect Dis.

ciz669, https://doi.org/10.1093/cid/ciz669

6. Schillie S, Vellozzi C, Reingold A, et al. Prevention of hepatitis B virus infection in the United States: Recommendations of the Advisory Committee on Immunization Practices. MMWR Recomm Rep 2018; 67:1-31

7. Ioannou GN, 2011. Hepatitis B virus in the United States: infection, exposure, and immunity rates in a nationally representative survey. Ann Intern Med. 2011;154(5):319-328.

8. Kushner T, Chen Z, Tressler S, et al. Trends in hepatitis B infection and immunity among women of childbearing age in the United States. Clin Infect Dis. 2019 Aug 26. doi:

$10.1093 / \mathrm{cid} / \mathrm{ciz} 841$

9. Schillie SF, Canary L, Koneru A, et al. Hepatitis C virus in women of childbearing age, pregnant women, and children. Am J Prev Med. 2018: 55(5):633-641.

10. Ly KN, Jiles RB, Teshale EH, Foster MA, Pesano RL, Holmberg SD. Hepatitis C virus infection among reproductive-aged women and children in the United States, 2006 to 2014. Ann Intern Med 2017; 166:775-82.

11. Koneru A, Nelson N, Hariri S, et al. Increased hepatitis C virus (HCV) detection in women of childbearing age and potential risk for vertical transmission-United States and Kentucky, 2011-2014. MMWR Morb Mortal Wkly Rep. 2016: 65(28):705-710. 
APPENDICES 


\section{APPENDIX 1}

Permission to reprint from Oxford Press

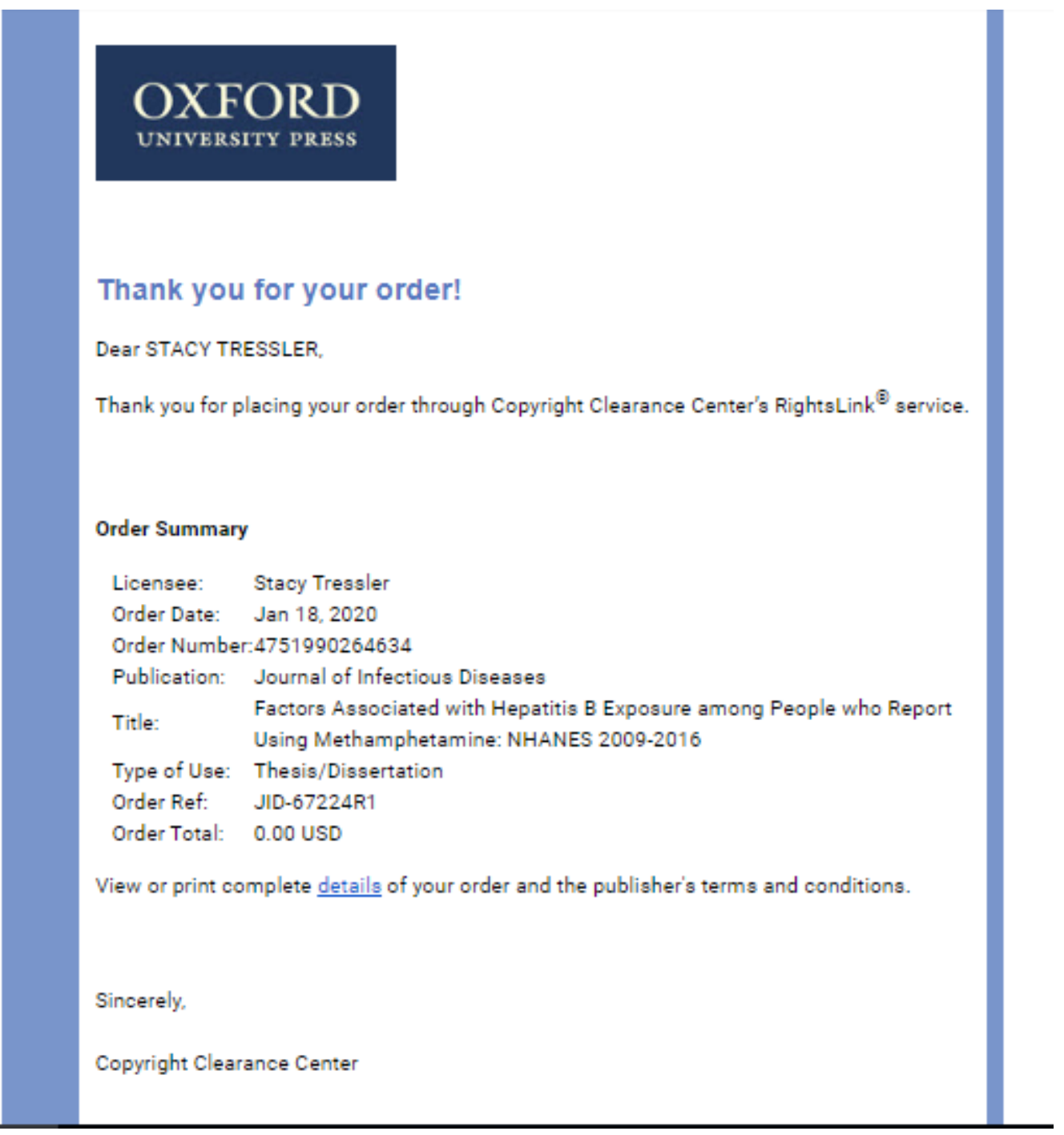

